San Jose State University

SJSU ScholarWorks

Master's Theses

Master's Theses and Graduate Research

1995

\title{
Effects of contextual interference on acquisition, retention, and transfer accuracy in shooting a moving soccer ball
}

\author{
Edward H. Mattson \\ San Jose State University
}

Follow this and additional works at: https://scholarworks.sjsu.edu/etd_theses

\section{Recommended Citation}

Mattson, Edward H., "Effects of contextual interference on acquisition, retention, and transfer accuracy in shooting a moving soccer ball" (1995). Master's Theses. 1013.

DOI: https://doi.org/10.31979/etd.sf3z-mraj

https://scholarworks.sjsu.edu/etd_theses/1013

This Thesis is brought to you for free and open access by the Master's Theses and Graduate Research at SJSU ScholarWorks. It has been accepted for inclusion in Master's Theses by an authorized administrator of SJSU ScholarWorks. For more information, please contact scholarworks@sjsu.edu. 


\section{INFORMATION TO USERS}

This manuscript has been reproduced from the microfilm master. UMI films the text directly from the original or copy submitted. Thus, some thesis and dissertation copies are in typewriter face, while others may be from any type of computer printer.

The quality of this reproduction is dependent upon the quality of the copy submitted. Broken or indistinct print, colored or poor quality illustrations and photographs, print bleedthrough, substandard margins, and improper alignment can adversely affect reproduction.

In the unlikely event that the author did not send UMI a complete manuscript and there are missing pages, these will be noted. Also, if unauthorized copyright material had to be removed, a note will indicate the deletion.

Oversize materials (e.g., maps, drawings, charts) are reproduced by sectioning the original, beginning at the upper left-hand corner and contimuing from left to right in equal sections with small overlaps. Each original is also photographed in one exposure and is included in reduced form at the back of the book.

Photographs included in the original manuscript have been reproduced xerographically in this copy. Higher quality $6^{\prime \prime} \times 9^{n}$ black and white photographic prints are available for any photographs or illustrations appearing in this copy for an additional charge. Contact UMI directly to order.

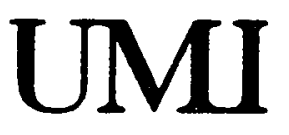

A Bell \& Howell information Company 



\title{
EFFECTS OF CONTEXTUAL INTERFERENCE ON ACQUISITION, RETENTION, AND TRANSFER ACCURACY \\ IN SHOOTING A MOVING SOCCER BALL
}

\author{
A Thesis \\ Presented to \\ The Faculty of the Department of Human Performance \\ San Jose State University
}

\author{
In Partial Fulfillment \\ of the Requirements for the Degree \\ Master of Arts
}

by

Edward H. Mattson

May, 1995 
UMI Number : 1374604

Copyright 1995 by

Mattson, Edward Harry

All rights reserved.

UMI Microform 1374604

Copyright 1995, by UMI Company. All rights reserved.

This microform edition is protected against unauthorized copying under Title 17, United States Code.

\section{UMI}

300 North Zeeb Road

Ann Arbor, MI 48103 
- 1995

Edward H. Mattson

ALL RIGHTS RESERVED 
APPROVED FOR THE DEPARTMENT OF HUMAN PERFORMANCE

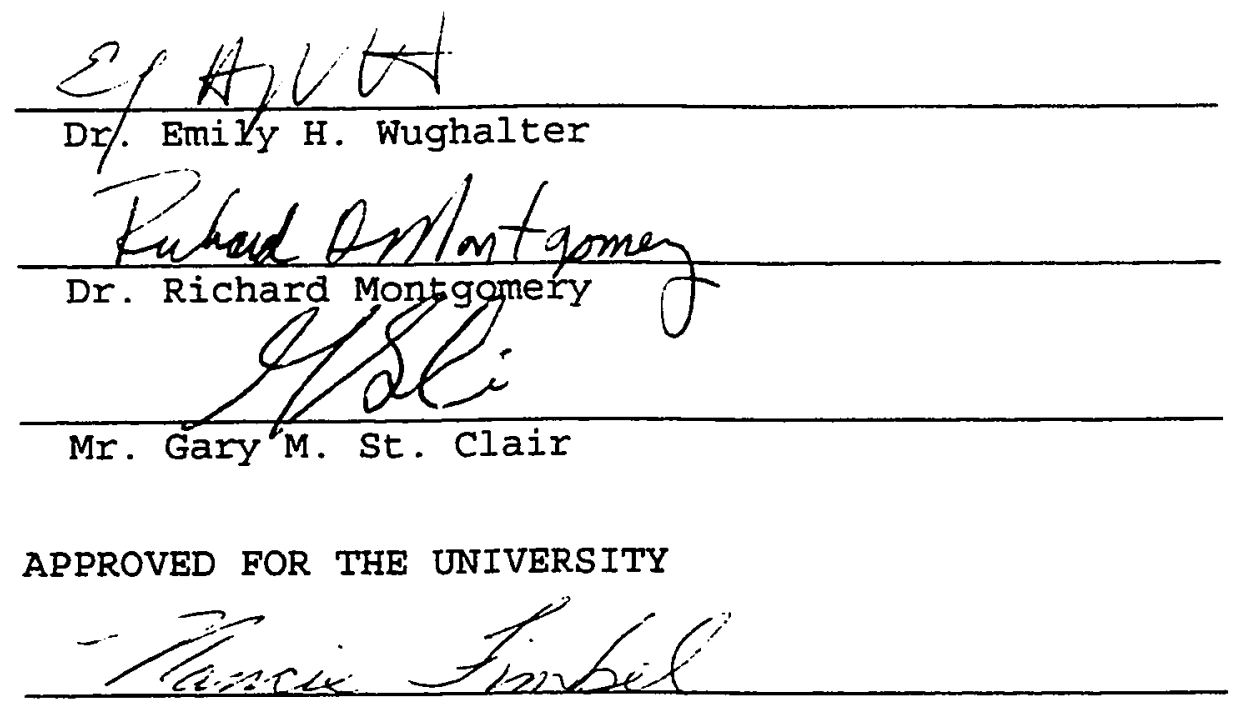


ABSTRACT

This study was proposed to investigate the generalizability of results of contextual interference effects on acquisition, retention and transfer of soccer shooting by extending previous laboratory research to a field setting.

A scoring target was developed to measure shooting accuracy. Seventeen female subjects, from 14 to 17 years old, with 5 to 11 years of soccer experience, were tested in either a serial or blocked practice format. Three days following acquisition, the retention and transfer phases were administered in a random order.

Analysis of covariance was used to analyze shooting accuracy scores. A pretest of three trials was administered. A 2 (Contextual Interference) x 3 (Trial Blocks) ANCOVA with repeated measures on the last factor was used to analyze acquisition shooting accuracy. Two separate one way ANCOVAs were used to analyze the effect of acquisition contextual interference on retention and transfer shooting accuracy.

No significant group difference was found during acquisition or retention. A significant group effect was found in the transfer phase $(F(1,14)=10.89, p<.05)$; the serial acquisition group $(M=3.39)$ had significantly greater shooting accuracy than the blocked acquisition group $(M=2 \cdot 31)$. 
DEDICATION

I would like to dedicate the pursuit of my education to my children, specifically to Diana, because of her love of play and having a good time in sports.

I would like to dedicate this research to the many athletes I have coached and will coach. May they always benefit from my coaching and become better athletes and individuals. 


\section{ACKNOWLEDGEMENTS}

I would like to extend my appreciation and gratitude to those individuals who actively participated in my completing this thesis and my master's degree.

To Dr. Barbara Conry, my philosophy instructor, who provided encouragement and gave me the confidence to continue the pursuit of my thesis and degree. I would not have attempted this without her faith in my abilities. To Mr. Mani Hernandez, one of my former coaches, who made time in his coaching season to help with this study. To Mr. Gary st. Clair, Committee Member, for his expertise in soccer, help in trying to finding subjects, and contributions to this thesis.

To Dr. Richard Montgomery, Committee Member and Advisor, for his patience, understanding, and willingness to assist me throughout my research.

To Dr. Emily Wughalter, Comittee Chair, for her expertise in motor learning, suggestions for a topic that has a practical application to my coaching career, and endless time and effort in assisting me to finish this thesis within the deadlines.

To my best friend, companion, and wife, Theresa, for her support, encouragement, listening abilities and endless hours of proof reading. Without her teamwork effort this thesis would never have been completed. We did it together. vi 
Table of Contents

Page Dedication . . . . . . . . . . . . . . . . . . . v Acknowledgements . . . . . . . . . . . . . . . . . . . vi Chapter 1 Introduction . . . . . . . . . . . . . . . . . 1

Statement of the Problem . . . . . . . . . . . . 3

Hypotheses . . . . . . . . . . . . . . . . . . . . 4

Delimitations . . . . . . . . . . . . . . . 4

Assumptions . . . . . . . . . . . . . . . . . . . 5

Definitions . . . . . . . . . . . . . . . . 5

Need for the study . . . . . . . . . . . . 7

Chapter 2 Review of Literature . . . . . . . . . . . 10

Contextual Interference Theory . . . . . . . . 10

Contextual Interference Applied

to Motor Learning . . . . . . . . . . . . . . . 14

Contextual Interference Field

Studies in Motor Learning . . . . . . . . . . . 21

Chapter 3 Methods . . . . . . . . . . . . . . . 24

Pilot study . . . . . . . . . . . . . . . . . . . 24

Subjects . . . . . . . . . . . . . . . . . 24

Apparatus . . . . . . . . . . . . . . . . 25

Procedures . . . . . . . . . . . . . . . . . 29

Results . . . . . . . . . . . . . . . . 32

Main Study . . . . . . . . . . . . . . . . . . . . 34

Subjects . . . . . . . . . . . . . . . . . 34

Apparatus . . . . . . . . . . . . . . . . . 35

vii 
Procedures . . . . . . . . . . . . . . . . 35

Design . . . . . . . . . . . . . . . 38

Analysis of Data. . . . . . . . . . . . . . 39

Chapter 4 Results . . . . . . . . . . . . . . . . 41

Descriptive/Analyses . . . . . . . . . . . . . 41

Analyses of Blocked
and Serial Groups . . . . . . . . . . . . . . . . 47

Acquisition . . . . . . . . . . . . . . . . . . 49

Retention and Transfer... . . . . . . . . 51

Summary of the Results . . . . . . . . . . . . 52

Chapter 5 Discussion . . . . . . . . . . . . 53

Pretest . . . . . . . . . . . . . . . . . 54

Acquisition . . . . . . . . . . . . . 55

Retention ............... . . 60

Transfer.................. . . 61

Summary . . . . . . . . . . . . . . . 62

Future Recommendations . . . . . . . . . . . . 63

References . . . . . . . . . . . . . . . 67

Appendices . . . . . . . . . . . . . . . . . . . . 71

Appendix A, Target Goal . . . . . . . . . . 71

Appendix B, Acquisition and Retention Locations
for Pilot Study . . . . . . . . 73

Appendix C, Consent Form for Pilot Study . . . 74

Appendix D, Descriptive Soccer Questionnaire
for Pilot Study . . . . . . . 76

Appendix E, Instructions for Pilot Study . . . . . 77 


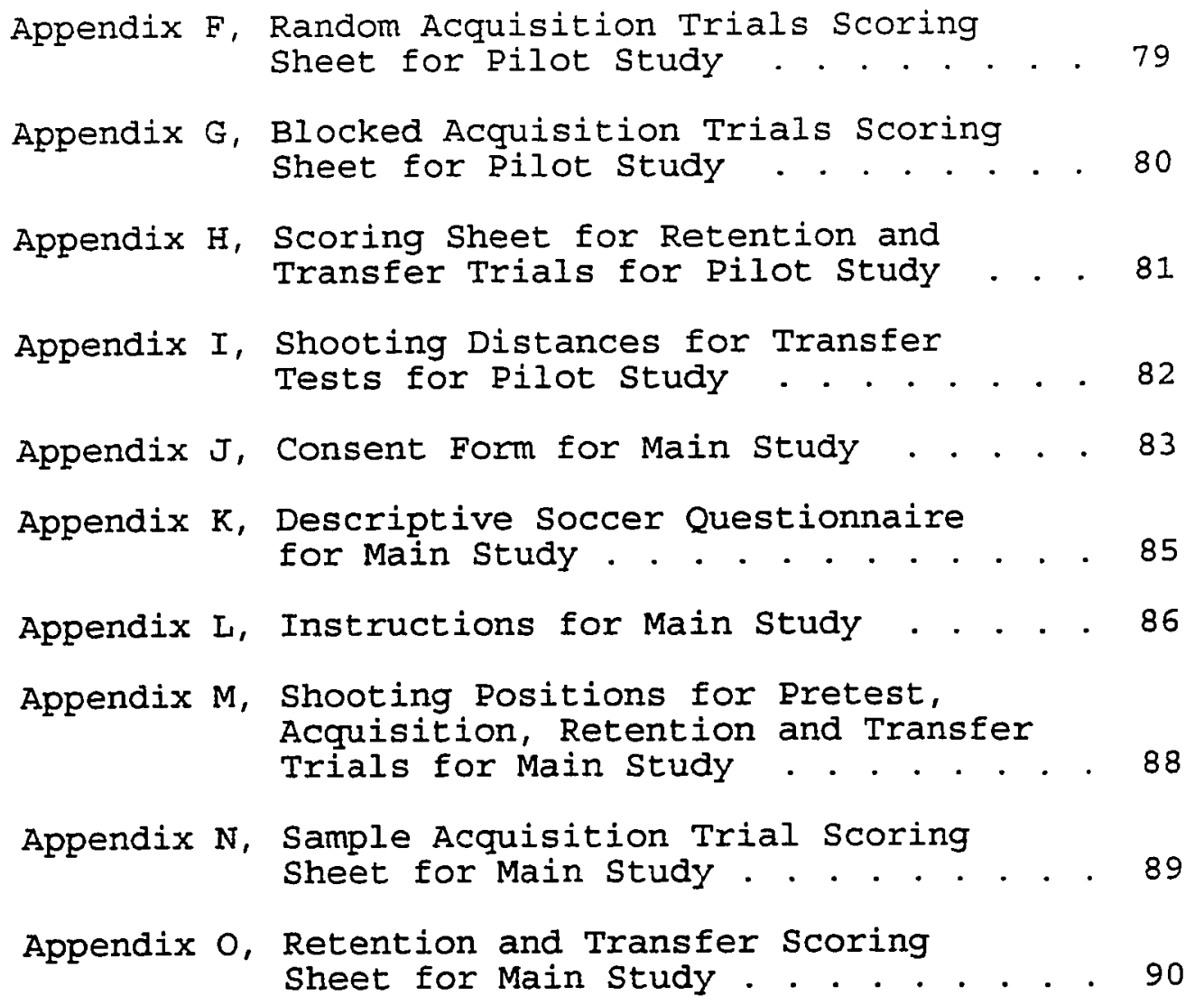


Table of Tables

Page

1. Distribution of Subjects in Each Group . . . . . . 41

2. Birth Year and Age Frequency and Percentage of Subjects by Group and Total Frequency and Percentage.................... . . 42

3. Total Soccer Experience Frequency and Percentage of Subjects by Group and Total Frequency and Percentage . . . . . . . . . . . . . . . . . . 43

4. Varsity Soccer Experience and Percentage of Subjects by Group and Total Frequency and Percentage . . . . . . . . . . . . . . . . . 44

5. Junior Varsity Experience Frequency and Percentage of Subject by Group and Total Total Frequency and Percentage. . . . . . . . . . 45

6. Varsity Experience Frequency and Percentage of Subjects by Group and Total Frequency and Percentage................. . . 45

7. Position Normally Played Frequency and Percentage of Subjects by Group and Total Frequency Percentage. . . . . . . . . . . . . . . . . 46

8. Goals Scored in the Past Two Seasons Frequency and Percentage of Subjects by Group and Total Frequency and Percentage . . . . . . . . . . . 48

9. Means by Trial Block and Acquisition Contextual Interference Group . . . . . . . . . . 49

10. Collapsed Acquisition Trial Block 1 Score Distribution of Placement Scores and Percentages by Point Values . . . . . . . . . . . . . . . . . 59

11. Blocked Group Placement Scores on the Target Goal by Acquisition . . . . . . . . . . . . . . . 60

12 Serial Group Placement Scores on the Target Goal by Acquisition Trial Block . . . . . . . . 60 


\section{Table of Figures}

Figure Page

1. Regulation soccer goal . . . . . . . . . . . . 25

2. Subdivided soccer goal into 4 by 4 with the numerical point value for each section. . . . . . 26

3. Soccer goal with the added section on the outside of the goal and the point value of one . . 26

4. Mean Scores Collapsed Over Blocked and Serial Groups During Acquisition Trial Blocks . . . . . . 50 
Chapter 1

\section{Introduction}

Some children begin to participate in organized team sports such as football, soccer, basketball, baseball and softball as early as six years of age. Coaches of children's teams are often volunteers who use their past personal experience, if they played, or rely on books (Hughes, 1980; O'Shea, 1986) for drills to teach skills to children.

Improved development of motor skills such as kicking, throwing, hitting and shooting is one of the expectations athletes, parents, and administrators have of coaches. One limitation encountered by coaches, in improving development of motor skills, is that practice is limited to an average of two times per week, approximately 90 minutes per session, and one game per week, (J. Asencio, personal communication, January 18, 1994, Police Athletic League director).

Volunteer coaches teach motor skills with limited amounts of practice time and limited knowledge of motor learning (Singer, 1990).

Laboratory studies have been conducted to understand the learning of motor skills. One theory which easily lends its hypotheses to practice is Battig's (1979) contextual interference theory. Shea and Morgan (1979) were the first to test Battig's hypothesis regarding contextual interference in motor skill learning. Their research was 
laboratory based. They found a random practice schedule produced significantly better retention and transfer scores than a blocked practice schedule.

In the contextual interference theory Battig (1979) suggested that a variety of skills can be learned, and retention and transfer will increase provided acquisition takes place in a randomly occurring order. He identified this type of random practice as high contextual interference. The alternative is to learn each skill individually, in a blocked acquisition format. In blocked practice one skill is tried over and over and practice on that task is completed before a new skill is presented. This blocked practice is identified as low contextual interference.

Shea and Morgan's (1979) study and subsequent studies conducted on contextual interference used laboratory conditions and laboratory devices such as a barrier knock down device (Shea \& Morgan, 1979), a pursuit rotor (Whitehurst \& Del Rey, 1983), or a Bassin Anticipation Timer (Del Rey, Whitehurst, Wughalter \& Barnwell, 1983; Del Rey, Wughalter, \& Carnes, 1987; Del Rey, Wughalter \& Whitehurst, 1982). On the other hand, some studies used previous laboratory findings and applied the findings to field studies using specific sports skills such as badminton (Goode \& Magill, 1986) and volleyball (Bortoli, Robazza, 
Durigon \& Carra, 1992; French, Rink, \& Werner, 1990). This study focused on the application of laboratory findings on the contextual interference effect in a soccer field study, a sport that requires eye-foot coordination. Gentile (1972) identified closed skills as skills performed in a stable or predictable environment and open skills as skills performed in a changing or unpredictable environment. For the most part laboratory studies on contextual interference have used closed skills instead of open skills or open skills where the variance in the environment can be controlled through technology. A benefit of closed skills is that variables related to environmental conditions can be controlled and the results can be attributed to the variables manipulated. The skill of shooting a moving ball at a target goal, an open skill, was used as the test for the study presented here.

Statement of the Problem

Many studies have been conducted by researchers in laboratory settings. These studies have been criticized for the lack of ecological validity (Kirk, 1989; Magill, 1990; Singer, 1990). In the present study the effects of acquisition contextual interference on acquisition, retention, and transfer of shooting accuracy of a soccer kick was determined. 
Hypotheses

The following null hypotheses were made for the purpose of this study:

1. Acquisition contextual interference will not affect shooting accuracy in acquisition.

2. Trial block will not affect shooting accuracy in acquisition .

3. Acquisition contextual interference and trials block will not affect shooting accuracy in acquisition.

4. Acquisition contextual interference will not affect shooting accuracy in retention.

5. Acquisition contextual interference will not affect shooting accuracy in transfer.

\section{Delimitations}

The delimitations of this study were:

1. Subjects were limited to female members of a local high school soccer team. All subjects participated on either the varsity or junior varsity soccer team during the 1994-1995 high school soccer season. Subjects ranged from 14 to 17 years of age and 9 th to 12 th grades. This age group allowed for the physical maturity to shoot at a goal from the designated distances.

2. Total soccer experience of subjects ranged from 5 to 11 years. This eliminated novices from participating in the study . 
3. Subjects used their dominant leg to strike the soccer ball with the inside of the foot (push pass) or the instep kick for the trials taken during the study.

4. The test site was limited to a level, dry, grassy field. The grass length was Iimited to a maximum of three inches. 5. Size 5 soccer balls manufactured by Mitre were used. This size ball has a circumference range of 27 to 28 inches, weight range of 14 to 16 pounds, and pressure of 15 pounds per square inch. Soccer balls were checked daily before beginning data collection to insure adherence to the desired specifications.

\section{Assumptions}

The following assumption was made for the purpose of the study:

The scoring method is a realistic representation of the probability of goal scoring in a real soccer game. The higher the score, the greater the probability of scoring a goal when a goalkeeper is protecting the goal.

\section{Definitions}

Contextual interference. Intrinsic and extraneous factors that create interference and affect subject's learning of tasks. For the purpose of this study the following operational definitions of contextual interference were used. 
High contextual interference. A practice schedule where task similarity, and contextual variety, (the manipulation of the practice schedule in a random sequence) are manipulated to create the greatest degree of interference with learning (Battig, 1979).

Low contextual interference. A practice schedule where task similarity is kept constant, and contextual variety (the use of the practice schedule in a blocked sequence, e.g., AAA..., BBB..., CCC...), is manipulated to create the least degree of interference while learning (Magill \& Hall, 1990).

Moderate contextual interference. A practice schedule where task similarity is kept constant (three different distances to kick the soccer ball at the goal) and contextual variety (the use of the practice schedule in a serial sequence, e.g., $A B C A B C A . .$.$) is manipulated to$ create interference with learning.

Goal scoring. The actual process of the entire soccer ball crossing the depth and moving within the boundaries of the target goal. A point is awarded to the opposing team regardless of which team last touched the soccer ball. The target area used in this study is subdivided and point values range from 1 to 6 points depending where the ball crosses the target area (Appendix A). If the target was completely missed, a score of zero was recorded. 
Inside kick. Kick executed with the inside (anterior)

portion of the foot, e.g., push pass.

Instep kick. Kick executed with the shoe-lace portion of the shoe (Ingels, Jr., 1975).

Penalty Area. The penalty area is an 18-by-44-yard area located directly in front of each goal (Appendix B). This is regulation marking on all soccer fields (Hughes, 1980). All distances used in the study fell within the range of the penalty area.

Penalty Spot. The place 12 yards in front of the center of the goal line from which penalty kicks are taken. The penalty spot was used as a shooting location during this study.

Shooting. Shooting in this study referred to kicking a soccer ball that was moving toward the goal and contacted at the assigned location with the intention of scoring a point. Need for the study

The study was designed to test the hypothesis advanced by william F. Battig in his contextual interference theory. The task incorporated an eye-foot coordination motor skill and a task in a field environment. Previous investigations have tested eye-hand coordination skills. The field task, shooting a moving soccer ball, was used because it is commonly used in the game of soccer. 
Shooting a moving soccer ball for accuracy from the designated distances is an open motor skill that occurs in a competitive soccer game. In this study, the external distractions (Gentile, 1972) and variables normally associated with a soccer game were controlled; these distractions include the presence of opposition and teammates and the need to control the ball that was received from another player. This established a testing environment that could be considered somewhat predictable and reproducible even while using an open motor skill. This is a step towards establishing the ecological validity of the contextual interference hypothesis.

Ecological validity and generalizability are issues that teachers and coaches may examine in trying to improve methodologies to improve player's motor skills. If researchers claim that high contextual interference findings can be readily applied to educational settings (Shea \& Morgan, 1979), new methodologies of teaching motor skills will have to emerge.

The application of a new method of teaching can be applied to the billions-of-dollar sports industry (Industry Survey, 1987) in California. This industry includes hundreds of specialized sports camps that are held yearly. Some of these camps run as much as $\$ 995$ per week per person (Vogelsinger, 1983). A large consumer market exists that is 
interested in learning how to play and teach sports. This market is willing to pay for professional instruction that is based upon solid motor learning principles. 
Chapter 2

Review of Literature

Contextual Interference Theory

Contextual interference theory originated in the domain of verbal memory (Battig, 1979). Later Shea and Morgan (1979) applied the theory to memory for motor skills. The major hypothesis of the theory is based upon the notion of creating high levels of interference during practice to improve the flexibility of memory. Controversies continue to exist in the motor learning literature regarding the best method of manipulating the variables to produce the optimal level of interference to facilitate learning (Magill \& Hall, 1990; Shea \& Morgan, 1979).

Battig presented a conceptualization of human memory that included eight closely related key features. They are multiple processing, variable processing, elaboration and organization, distinctiveness, contextual factors, contextual interference, contextual variety and encodingretrieval congruence. The purpose of his conceptualization was to provide a view to explain processing of information and the flexibility of human memory. In contextual interference theory, Battig (1979) discussed human memory and learning as a complex and flexible process. He also suggested that one method of learning cannot be applied to 
numerous individual's or to the same individual on different situations.

According to Battig (1979) and Shea and Morgan (1979) multiple processing occurs when an individual uses many different processing methods and these are processed simultaneously in working memory. Variable processing occurs when an individual uses different strategies to process the same information in similar situations.

New information is stored in memory regardless of the differences or similarities to previously stored information. Since the purpose of storing information is to be able to retrieve it at a later date quickly and accurately, human memory has an elaborate organizational system for storing information (Battig, 1979).

Battig referred to distinctiveness as the ability to distinguish characteristics of similar tasks, affecting task similarity. The more closely related the information is to previous information, the more important it becomes to identify smaller differences so information is not stored and confused with previous information. In a verbal protocol analysis Shea and zimny (1988) found that subjects in a high task similarity group made numerous comments regarding the differences between the tasks compared to the low task similarity groups. 
Originally Battig (1979) labelled this process of learning intratask interference but felt the term was misleading because extraneous factors, termed contextual factors, such as task and practice schedule, also cause interference. Therefore, he revised his ideas and developed his notions regarding contextual interference (Battig, 1979). In order to test the contextual interference hypothesis researchers have manipulated the contextual factors which allow different levels of contextual interference, i.e., high or low contextual interference (Goode \& Magill, 1986; Shea \& Morgan, 1979; Shea \& Zimny, 1988; Wulf \& Lee, 1993). Contextual variety is the manipulation of the contextual factors through the changes that occur within and across repeated trials, e.g., random and blocked practice schedule formats.

Battig's position on the benefits of random practice scheduling coincides with Jacoby's (1978) position on learning. Jacoby hypothesized if an individual is given a mathematical problem, problem solving techniques will be used to find a solution. If the same problem is presented immediately following the solution, memorization will be used instead of problem solving techniques (Shea \& Zimny, 1983). Shea and Morgan's (1979) findings are in agreement with Battig and Jacoby, because the following is given as a possible explanation: 
In the present experiment, performance in the high contextual interference condition was more difficult than in the low contextual interference condition, and the random group was forced to use multiple processing strategies to optimize its performance during acquisition, whereas no such multiple processing was necessary for the blocked group. This greater elaboration led to better retention performance, especially when the context of performance was changed, as well as, improved transfer. (p. 186)

The ability to retrieve stored or encoded information is known as encoding-retrieval specificity. Performance scores on retention and transfer tests are the indicators of how well elaborate organization and distinctiveness have worked together and a measure of the strength of memory. Magill and Hall (1990) discussed memory in terms of motor program formulation. They agreed with Battig (1979) that random practice schedules produce high interference and contextual variety. However, according to Magill and Hall task similarity produces low levels of interference.

Magill and Hall's hypothesis is based upon whether the tasks are controlled by the same motor program or different motor programs, such as in ball throwing. If a ball is thrown in three different throwing patterns such as overhand, underhand or sidearm, then a different motor program is used in each situation versus throwing a ball overhand from three different distances which uses the same motor program (Magill \& Hall, 1990). 
Magill and Hall's (1990) hypotheses grew out of those provided by Lee and Magill (1985) that motor program tasks are reconstructed in memory each time they are needed. To reconstruct a motor program that is different from the previous motor program requires more elaborate processing and creates higher interference than reconstruction of a similar motor program. Based upon the reconstruction hypothesis, Magill and Hall argued that the use of different motor programs produces higher interference and in turn produces higher contextual interference than the use of similar tasks as argued by Battig. Studies have been conducted to test both Battig's (1979) and Magill and Hall's (1990) hypotheses.

\section{Contextual Interference Applied to Motor Learning}

The first study of contextual interference and motor skills was conducted by Shea and Morgan (1979). It was designed to study two acquisition contexts, blocked and random. The effects of each group on retention at two different time intervals, and transfer to a novel task were studied. Shea and Morgan (1979) found that blocked groups scored better than random groups during acquisition, but random groups had significantly better test scores during retention and transfer. The findings supported Battig's (1979) notion that high contextual interference improved 
retention and transfer scores better than low contextual interference.

Each acquisition group was administered three acquisition tasks, divided among three trial blocks of 18 trials each. Each group received a total of 54 acquisition trials, 18 trials per task. The blocked group, classified as low contextual interference, practiced only one acquisition task per trial block before practicing a new task. The random group, classified as high contextual interference, practiced each of the three acquisition tasks during each trial block. Prior to the onset of the trial, subjects in the random group did not have knowledge of the required task, and they never performed more than two consecutive trials of the same task.

The two acquisition groups were subdivided into two retention groups. One was tested 10 minutes after the last acquisition set and the other was tested after 10 days. This provided four retention test groups: blocked acquisition with 10-minute delay retention; blocked acquisition with 10-day delay; random acquisition with 10minute delay; and, random acquisition with 10-day delay. Each group received 18 retention trials across the 3 acquisition tasks; 9 were administered in a blocked sequence and 9 in a random sequence. A total of 6 trials per task, 3 in a blocked sequence and 3 in a random sequence, were 
tested. Immediately after the retention test each group received a transfer test consisting of one set of three trials on each of two novel transfer tasks, one easier and one more difficult than the acquisition and retention tasks.

The tasks required that the subjects knock down three of the six barriers in a particular sequence located on a barrier knock down apparatus. If an error was made in the sequence, the subject performed that particular trial immediately after the 18 trials of the set were completed. The blocked acquisition group scored better than the random group during the acquisition. Shea and Zimny (1988) believed the faster reaction times and movement times were the result of subjects memorizing the task and storing only one task in working memory at a time. The random group could not memorize the task or store it in working memory because of the random presentation of tasks. This may have caused slower movement times for random groups during acquisition when compared to blocked groups.

Various paradigms have been used to test the contextual interference hypothesis. The paradigm used by shea and Morgan (1979) was blocked and random administration of tasks during acquisition, retention, and transfer. Researchers (Bortoli et al., 1992; Del Rey, et al. 1982; Lee \& Magill, 1983; Shea \& Titzer, 1993; Wright, Li, \& Whitacre, 1992) 
have varied the paradigm used based upon the focus of the their study.

Four types of acquisition contexts have been used: blocked, random, constant and serial. Shea and Morgan used blocked and random acquisition groups and many studies have incorporated both groups in their studies (Del Rey et al. 1987; Del Rey et al. 1983; Del Rey et al. 1982; Lee \& Magill, 1983; Whitehurst \& Del Rey, 1983; Wood \& Ging, 1991) with similar results.

A method of presenting tasks during acquisition is in a serial order (Bortoli et al., 1992; Goode \& Magill, 1986; Lee \& Magill, 1983). A serial format permits subjects prior knowledge of a predetermined practice order during acquisition (e.g., 132132132...). Lee and Magill (1983) conducted a laboratory study to investigate if the random group's higher performance scores during retention and transfer were due to a lack of knowledge of the sequence of tasks or whether the rotation of tasks was the contributing factor.

Serial group studies have produced conflicting results. Lee and Magill (1983) found significantly better retention and transfer scores for serial than for blocked groups. The findings were similar to random group results. Bortoli et al. (1992), and Goode \& Magill (1986) did not find better group retention scores in the serial group than in the 
blocked group. However, Bortoli et al. (1992) did find significantly better transfer scores on the long serve transfer test. The preliminary findings are contradictory but more research is needed to determine which factors within serial practice contribute to better retention and transfer.

Shea and Morgan's (1979) paradigm included both blocked and random testing during retention and transfer. Other studies used the blocked and random paradigm only during retention testing (Del Rey et al. 1987), and others used the paradigm only during transfer (Del Rey et al. 1983; Del Rey et al. 1982). Other studies only used blocked (Wood \& Ging, 1991; Wright, Li, \& Whitacre, 1992; Wrisberg \& Liu, 1991), random (Goode \& Magill, 1986; Lee \& Magill, 1983), or predetermined order, similar to serial format (Bortoli et al.,1992), during retention testing. Yet others used only blocked (Del Rey et al., 1987; Wood \& Ging, 1991; Wrisberg \& Liu, 1991), random (Goode \& Magill, 1986), predetermined order (Bortoli et al. 1992) during transfer testing.

Some studies did not incorporate a retention test (Del Rey et al., 1982) and some did not use a transfer test (French et al., 1990). A possible explanation for the differences in paradigms may be the varying scope of the individual studies. Lee, Wulf, and Schmidt (1992) stated that retention tests require subjects to recall previously 
practiced tasks; whereas transfer tests require subjects to extrapolate from previously practiced tasks to perform novel tasks. Some studies may have studied only a particular area of the contextual interference theory (Lee, 1988). Many studies did not offer an explanation as to the rationale for the paradigm used. Goode and Magill (1986) offered the following explanation for the random only paradigm for retention and transfer testing:

The general goal of practice is to transfer to a game. A game situation varies from event to event, making random testing the best condition to appraise the effectiveness of practice. (p. 312)

Wrisberg and Liu (1991) supported random testing because it simulates game conditions.

Magill and Hall's interpretation of high contextual interference through task dissimilarity requires a different methodology of transfer testing when compared to shea and Morgan. Shea and Morgan's paradigm used a set of transfer tasks per study because the acquisition tasks were similar. Bortoli et al. (1992) used Magill and Hall's interpretation of contextual interference and found the need to establish a set of transfer tasks for each of the dissimilar acquisition tasks.

The tasks used to test contextual interference are categorized into laboratory or non laboratory (field tasks) and similar or different motor programs. The laboratory 
tasks have been eye-hand coordination and time measurement skills. The tasks have included knocking down barriers (Lee \& Magil1, 1983; Shea \& Morgan, 1979; Shea \& Titzer, 1993), coincidence anticipation (Del Rey et al. 1987; Del Rey et al. 1983; Del Rey et al. 1982), pressing a specific sequence of keys (Wright et al. 1992; Wulf \& Lee, 1993), movement patterns using a stimulus panel and a response board (Wood \& Ging, 1991), and pursuit tracking (Dunham Jr., Lemke, \& Moran, 1991; Whitehurst \& Del Rey, 1983). Many of the tasks measure time and do not provide for a score of zero.

Fewer field studies have been conducted than laboratory studies. Field tasks have included badminton serving (Goode \& Magill, 1986; Wrisberg \& Liu, 1991) and the volleyball skills of bumping, serving and overhand passing (Bortoli et al. 1992; French et al. 1990).

All of the studies that used laboratory tasks and field studies using badminton serving used similar motor program skills. Two studies that used a pursuit tracking device did not support a contextual interference effect (Dunham, Jr. et al. 1991; Whitehurst \& Del Rey, 1983). A possible explanation was that not enough cognitive processing was required to produce a high level of contextual interference when incorporated with random practice schedule.

Only two field studies were found that used different motor program skills: Bortoli et al. (1992) and French et 
al. (1990) both used volleyball skills. Bortoli et al.

(1992) used one retention and two transfer tests per acquisition skill and found a significant contextual interference effect between groups in the long transfer test for serving. French et al. (1990) did not find a contextual interference effect. A possible explanation offered by French et al. (1990) was that the subjects' skill level was too low to benefit from a random practice schedule.

Performance errors have occurred in both laboratory and field studies (Goode \& Magill, 1986; Shea \& Morgan, 1979; Shea \& Titzer, 1993), and researchers have indicated that subjects who did not perform the appropriate motor pattern were given retrials at the end of a block of trials. Contextual Interference Field studies in Motor Learning

There is continuous debate regarding the ecological validity of laboratory studies (Heuer, 1988; Kirk, 1989). The teacher and coach work in an environment that cannot control variables to replicate laboratory settings. Goode and Magill (1986) examined instructional textbooks and found that the lesson plans followed blocked practice models and disregarded contextual interference models. Goode and Magill concluded that theoretical models will not be adopted into instructional material until laboratory studies are practically applied through field tests. 
Field studies have been conducted in schools and sports camps (Browning \& Schack, 1990; Burton \& Welch, 1990; Goode \& Magill, 1986; Gusthart \& Kelly, 1991; Hopper, Guthrie \& Kelly 1991; Wrisberg \& Liu, 1991). Researchers have tried to replicate the findings of laboratory studies and at times are not able to produce similar results. This may be caused by researchers' inability to control or change variables, such as not using the same type of measuring devices or using game-like scoring methods.

Laboratory studies have used more sensitive measuring devices that are able to discriminate small differences in performances (e.g., time measurements in milliseconds). Field studies use measuring devices that are not as continuous as laboratory measuring devices. In field studies the outcomes are more dichotomous; for example, if a basketball player shoots a basketball, there are only two possible outcomes, either a basket or a missed shot. No points are awarded for hitting the backboard, rim, net or combination, and there is no greater penalty for shooting an air ball.

Laboratory studies need to address real life consequences that teachers and coaches face, to provide ecological validity (Welford, 1988). Studies that apply laboratory findings with game-type performance scoring (Wrisberg \& Liu, 1991) will allow researchers to use the 
same scoring methods in field studies, and this may increase the probability of finding similar results. Field studies that produce significant results produce ecological validity and may encourage authors to incorporate laboratory theories in instructional books. 


\section{Chapter 3}

Methods

Many studies have been conducted by researchers in laboratory settings. These studies have been criticized for the lack of ecological validity (Kirk, 1989; Magill, 1990;

singer, 1990). In the present study the effects of acquisition contextual interference on acquisition, retention, and transfer of shooting accuracy of a soccer kick was determined. In the following paragraphs the details of the pilot study and how the pilot influenced the main study are discussed.

Pilot study

A pilot study was conducted to test out the target scoring device and the manipulations required by the breakdown of the independent variables.

\section{Subjects}

Subjects were male volunteer members of an under-16year-old soccer team that was registered with California Youth Soccer Association (CYSA). The subjects were born in either 1979 or 1980 and were not older than 15 years old at the time of the study.

Subjects had from 5 to 11 years of prior soccer playing experience before participating in the study. This assured that subjects had had exposure to basic instruction in kicking a soccer ball. 


\section{Apparatus}

A practice soccer field normally used by club teams was used to conduct the investigation. A target goal scoring device was developed and used (Appendix A). It was comprised of a regulation size soccer goal 24 feet wide by 8 feet high (Figure 1 ) and was subdivided into 4 -foot by 4-

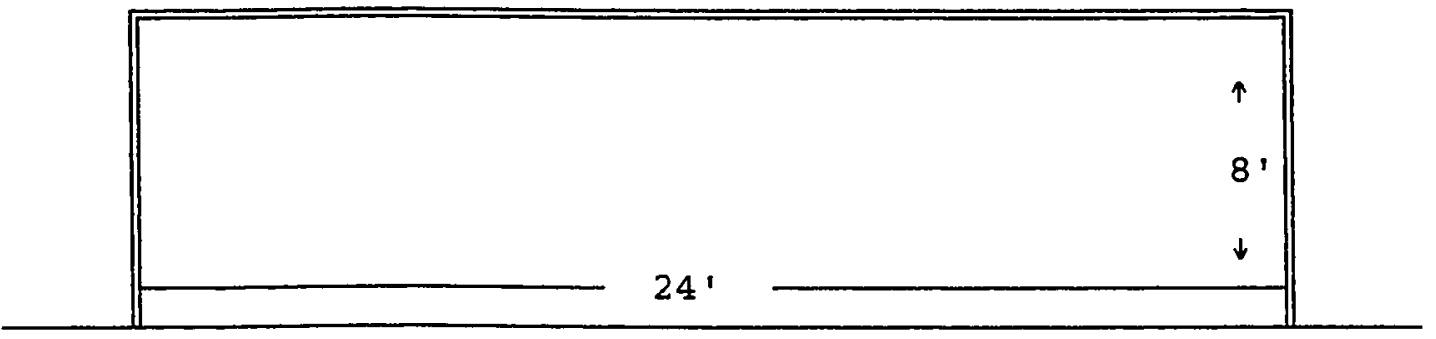

\section{Figure 1}

Regulation soccer goal.

foot square sections, each of which was given a numerical value to allow more accurate scoring, as depicted in Figure 2. 


\begin{tabular}{|l|l|l|l|l|l|}
\hline 6 & 4 & 2 & 2 & 4 & 6 \\
\hline 5 & 3 & 2 & 2 & 3 & 5 \\
\hline
\end{tabular}

Figure 2

Subdivided soccer goal into 4 by 4 foot squares with the numerical point value for each section.

In addition a 4-foot high by 3 -foot wide section outside of the goal (Figure 3) was added to the soccer goal and assigned a point value of one.

\begin{tabular}{|l|l|l|l|l|l|l||}
\hline 6 & 4 & 2 & 2 & 4 & 6 \\
\hline 1 & 5 & 3 & 2 & 2 & 3 & 5 \\
1 \\
\hline
\end{tabular}

\section{Figure 3}

Soccer goal with the added section on the outside of the goal and the point value of one.

The purpose of extending the soccer goal beyond the dimensions of a regulation soccer goal was to reward the shooter when a shot was low and just wide of the goal. A goalkeeper would most likely attempt to stop a shot close to 
the edge of the soccer goal. Any shot that a goalkeeper attempts to stop is considered a good shot because it may be deflected and playable by the shooter's teammate in a real game situation.

The apparatus developed for the study had not been used before but was presented to soccer, motor learning, and statistical authorities for content validity. The varsity soccer coach at San Jose State University provided recommendations as to which areas of the goal have higher probability of scoring goals than others. In addition, he suggested an area 4 feet high and 3 feet wide of the goalpost to be included as part of the target goal. A shot in the additional area would force a goalkeeper to react in an attempt to stop the shot because of an inability to determine if the shot is wide of the goal.

The scoring system was designed to allow higher point values to correspond with higher probabilities of scoring a goal when a goalkeeper is protecting the goal in a real game. All point values indicate that the soccer ball has passed through the goal, with the two exceptions of the 4foot high by 3 -foot wide area outside of the goalpost which is given one point. One point was also awarded when the ball hit the perimeter of the goal and rebounded into play. This was allowed because a secondary scoring opportunity is possible if the ball was maintained in the area of play. A 
zero point value was awarded if the ball was deflected outside of the playing field.

The soccer goal consists of two goal posts (side posts) and a crossbar (the horizontal bar connecting the goal posts). These posts are usually 4 inches wide and flat. The inside dimensions of the goal are 24 feet wide and 8 feet high. For the purpose of this study the inside dimensions were subdivided into 12,4 -foot by 4 -foot areas sectioned off with a rope. If the ball hit the rope, then the lesser point value of the two scoring areas which were divided by that part of the rope was given. The section wide of the goal was a 4-foot high by 3-foot wide area sectioned horizontally by rope and vertically by PVC pipe and a goal post. If the ball hit the rope, PVC pipe or goal post, or went in between the rope, PVC pipe, and goal post, one point was awarded.

The target goal was presented to two soccer authorities, a college Division I mens' varsity soccer coach with Division I goal keeping playing experience, and a high school girls' varsity soccer coach with professional and olympic soccer playing experience, for content validity. It is believed that the apparatus measured shooting accuracy, and the results can be replicated. 


\section{Procedures}

One test site and team was used to measure the soccer kick on the desired number of subjects. The researcher approached coaches through the commissioner of the local CYSA district. The test site was limited to a level, dry, grassy field.

Subjects attended practice at the beginning of the soccer season. The researcher approached athletes and coaches to explain that the study was an investigation for the completion of a thesis in Human Performance. All subjects and one of their guardians were given a consent form (Appendix C) and a descriptive soccer experience questionnaire (Appendix D).

Three pretest trials were conducted. The kicking point was 16 yards directly in front of the middle of the goal. A stratified sampling was used based upon subjects' answers to the descriptive soccer experience questionnaire. Subjects were assigned to one of two practice groups: blocked or random based on whether the subjects normally kicked free kicks, position played and total soccer experience.

Subjects were instructed that, shooting the ball was limited to the use of the inside of the foot or the instep kick (Appendix E). Subjects were not allowed to use the toe or outside of the foot to kick. If an improper kick was used, a retrial was assigned for the trial. Subjects were 
instructed to focus on accuracy, and to try to obtain the greatest number of points possible. Subjects were shown a design of the target goal (Appendix A) before the study and the design was available throughout the study as a reference.

Three acquisition shooting distances were used to measure the direct free shots. The shots simulated a direct free kick shot in a game situation. All shots occurred from the center of the goal out to one of three distances: 12, 18 or 22 yards away from the goal (Appendix B). These three distances are realistic distances for a direct free kick during a game situation.

The 12-yard distance is used when a penalty kick has been awarded. A penalty kick occurs when a major infraction of the rules has occurred in the penalty area. The ball is moved to the penalty spot. The player has the opportunity to place the ball down and to get set up; and then awaits the referee's signal to shoot the ball. In this situation it is only the goalkeeper and the shooter in the penalty area, all other players are outside of the penalty area until the shot has been taken.

The 18-yard distance was the closest distance that a direct free kick can be taken without it being a penalty kick. The 22-yard distance was a second distance to test a direct free kick outside of the penalty area. The ball was 
placed on the ground by the player simulating a game situation. The difference in this study as compared to a game situation is that in a game situation defenders stand a minimum of 10 yards away from the ball and will usually stand together forming a human wall to protect a portion of the goal. The purpose of the target goal scoring design is to allow higher points in the areas where the greater probability for a goal can be scored when defenders are in the game.

The acquisition phase consisted of 1 set of 9 trials and 2 sets of 12 trials, in one week, for a total of 33 trials for the acquisition portion of the experiment. The acquisition, retention and transfer sessions followed an order similar to a team practice schedule; each subject shot once and then another subject went and shot in a rotating order. Each subject retrieved his own ball before shooting again.

At the test site the team of 14 players was divided into blocked or random practice groups and tested. Each group of 7 subjects completed his set of trials before the next group began. Acquisition sessions were scheduled on three consecutive days, and the retention and transfer sessions followed two days later.

Random group subjects had 3 trials at each distance per set, with no more than 2 consecutive trials from the same 
distance. At the end of each acquisition day each subject had 4 trials at each distance for a total of 12 trials per day (Appendix F) .

Blocked group subjects had 12 trials per day at only one distance. The subjects' order of distances for the blocked groups was counterbalanced through each set and session (Appendix G). One subject shot from 12, 18 and 22 yards on days 1,2 , and 3 respectively; another subject shot from 18, 22, 12 yards on days 1, 2, and 3 respectively; and another subject shot from 22, 12 and 18 yards on days 1, 2, and 3 respectively.

A two day delayed retention test was administered and consisted of 9-random trials with 3 attempts per each distance and with no more than 2 consecutive shots from the same distance (Appendix H). This was done to simulate a game situation of varied shots (Goode \& Magill, 1986). The transfer test followed the retention test and consisted of 3 random trials from two novel shooting distances (Appendix I), 20 yards, (within the acquisition distances) and 25 yards, (outside the acquisition distances).

\section{Results}

The use of a stationary ball while kicking produced substantial problems. First, one of the assumptions was that players would try to improve. Many subjects lack knowledge of how to position a stationary soccer to produce 
accurate results. Most of the subjects elevated the soccer ball on top of a patch of grass, similar to placing a golf ball on a tee to hit. This caused many shots going high and wide. The players appeared to be interested only in kicking the ball as hard they could and accuracy was not a concern.

A second problem was the time factor involved with testing the random group in particular. The process of telling the player from which spot to shoot and then waiting for the player to set the ball up and then shoot was time consuming. No more than seven subjects participated on any one day for either group. The random group required approximately 35 minutes to complete one set of 12 shots. Both groups together required almost an hour to complete a session.

This lengthy delay frustrated the coach of the team. On the first day, the coach allowed the groups only to complete the pretest, which was a total 3 trials, and only 9 acquisition trials. The coach became frustrated when he noticed that most of his players where not taking the study seriously. When the players were approached they responded that this drill did not have any value for them because they did not take free kicks in a game and that the study was boring.

At the end of the pilot study, the coach mentioned that if he knew before the study began of the time commitment and 
the players' attitude, he would not have participated. He also mentioned that he could not recommend any other coach to commit to this study. If I could have found a way to speed up the process and have kept the subjects interested, then he might have reconsidered recommending the participation to another coach.

The coach mentioned he liked the scoring apparatus. He mentioned he understood the necessity for research but if I wanted to do a field study, I needed to make the study fit within realistic parameters, i.e., shooting practice for no more than 30 minutes. The coach was correct, I could not find any more coaches who were willing to participate. Some cited one or both of the above mentioned reasons as causes not to participate. These recommendations were investigated and helped develop the format for the main study. No statistics were completed because only four subjects per group completed all phases of the pilot study. Main study

The main study was conducted to further test the target scoring device and to test a revised set of independent variables due to the pilot study.

\section{Subjects}

Subjects were female volunteer members of a local girls' high school soccer team, who would be playing on either the junior varsity or varsity soccer teams but were 
trying out for the varsity soccer team. Players ranged from 14 to 17 years of age. The subjects ranged from freshman to seniors.

Subjects had from 5 to 11 years of prior soccer playing experience before participating in the study. This assured that the subjects had been exposed to basic instruction in kicking a soccer ball. This level of experience was chosen because Del Rey et al. (1982) and French et al. (1990) believed that the possible reason the novice or inexperienced subjects in their studies did not benefit from high contextual interference was directly related to the subjects' low level of experience.

\section{Apparatus}

A practice soccer field normally used by the soccer team was used to conduct the investigation and met all delimitations. The target goal scoring device used in the pilot study was used again in the main study (Appendix A).

\section{Procedures}

The researcher approached the varsity soccer coach and the coach selected one of the teams' practice sites as the test site. Four days were used to measure the shooting accuracy of the subjects. The coach selected 20 players who were going to play on either the varsity or junior varsity soccer team during the current season. Some players were 
trying out for varsity soccer, and the others were the better junior varsity players, as ranked by the coach. Subjects were attending practice at the beginning of the soccer season. The researcher approached the athletes and explained that the study was an investigation for the completion of a thesis in Human Performance. All subjects and one of their guardians were given a consent form (Appendix J) that was signed and returned. A descriptive soccer questionnaire (Appendix $K$ ) was returned on the first day of testing.

Three pretest trials were conducted from a distance of 12 yards directly in front of the middle of the goal. A random sampling was used to assign subjects to one of two practice groups: blocked or serial. The groups were assigned prior to collecting the questionnaire and prior to the beginning of the study. The coach's goal was to have one group participate in the study while the other group practiced other skills and so as not to waste practice time.

Subjects were instructed that shooting the ball was limited to the use of the inside of the foot or instep kick (Appendix L). Subjects where not allowed to use the toe or outside of the foot to kick. If an error occurred, a retrial was administered at the end of the trial block. Subjects were instructed to focus on accuracy and to try to obtain the greatest number of points possible. 
Three acquisition shooting distances were used to measure shooting accuracy. All shots occurred from directly in front of the goal at one of three distances: 12 yards directly in front of the left goal post, 15 yards directly in front of the center of the goal ( 3 yards behind the penalty spot), and 18 yards directly in front of the right goal post (Appendix M) .

The acquisition phase consisted of one set of 12 trials per day, three sessions in one week, for a total of 36 trials for the acquisition portion of the experiment. The acquisition, retention and transfer sessions followed a similar team practice schedule; each subject shot once and then another subject shot in a rotating order. Each subject retrieved her ball before shooting again.

Twenty players were divided into a blocked or serial practice group and tested. Each group of 10 subjects completed the one set of trials before the next group shot. Acquisition sessions were scheduled on three alternating days, Monday, Wednesday and Friday. The retention and transfer sessions follow three days later on the following Monday.

Serial group subjects had four trials at each distance per set, with a predetermined rotating order each day. At the end of the acquisition phase, each subject had 12 trials at each distance (Appendix N). 
Blocked group subjects had 12 trials at only one distance per set each day. The subjects' order of distances for the blocked groups was counterbalanced through each set and session (Appendix N). One subject shot from 12, 15 and 18 yards on days 1, 2, and 3 respectively. Another subject shot from 15, 18, 12 yards on days 1, 2, and 3 respectively. Another subject shot from 18, 12 and 15 yards on days 1,2 , and 3 respectively.

A three day delayed retention test was administered and consisted of 9-random trials with 3 attempts per each distance, with no more than 2 consecutive shots from the same distance (Appendix 0). This was done to simulate a game situation of varied shots (Goode \& Magill, 1986). The transfer test followed the retention test and consisted of 3-random trials from two novel shooting distances (Appendix M); 12 yards in front of the right goal post and 18 yards in front of the left goal post.

Design

In order to determine power of the study, an effect size of .80 was used. A sufficient number of studies have demonstrated support for a contextual interference effect. The blocked and serial groups each consisted of 10 subjects. An alpha level of .05 was established for this study. Based upon these data the power of the design was determined to be .30 . 
The independent variable acquisition contextual interference had two levels: serial practice and blocked practice. The independent variable shooting distances had three levels: 12 yards in front of left goal post, 15 yards directly in front of the center of the goal and 18 yards in front of the right goal post. The dependent variable used in the experiment was the shooting accuracy scores on the target for each trial. Subjects were able to achieve a maximum score of 216 points and a minimum of 0 points during acquisition phase. A maximum of 54 points and a minimum of

0 points was possible during the retention phase. A maximum of 36 points and a minimum of 0 points was possible during the transfer phase.

\section{Analysis of Data}

The acquisition data were analyzed in a 2 (Contextual Interference) $\times 3$ (Trial Block) analysis of covariance (ANCOVA) with repeated measures on the last factor on shooting accuracy scores. A pretest of three random trials from 12 yards in front of the goal was administered. The mean of the pretest trials was used as a covariate. Two independent variables were studied. The independent variable acquisition contextual interference had two levels, serial and blocked. The independent variable trial block had three levels, the first 12 trials, the second 12 trials, 
and the third 12 trials. The dependent variable shooting accuracy is an interval measure.

Two one way ANCOVAs were used to analyze acquisition contextual interference effects on retention and transfer shooting accuracy. In addition, a T-test was conducted on the pretest mean scores to determine if there was a significant difference between blocked and serial groups at the onset of the study. 
Chapter 4

Results

Descriptive/Analyses

The blocked and serial acquisition groups each consisted of 10 female subjects. Three subjects failed to complete the retention and transfer phases of the study; therefore, a total of 17 subjects completed the experiment. Nine of these subjects were in the blocked and eight subjects were in the serial group. The number and percentages are depicted in Table 1 . Statistics were calculated on the 17 subjects that completed the protocol for the study.

Table 1

Distribution of Subjects in Each Group

\begin{tabular}{ccc}
\hline Group & $\mathrm{n}$ & \% \\
\hline Blocked & 9 & 53 \\
Serial & 8 & 47 \\
Total & 17 & 100 \\
\hline
\end{tabular}

The following descriptive data were collected from the descriptive soccer questionnaire prior to beginning the experimental design for the study. In Table 2 the frequencies and percentages in relation to either blocked or serial group, as well as the combined total are detailed. 
The age distribution revealed three 17 year olds, one blocked and two serial; three 16 year olds, two blocked and one serial; four 15 year olds, none blocked and four serial; Table 2

Birth Year and Age Frequency and Percentage of Subjects by Group and Total Freguency and Percentage

\begin{tabular}{|c|c|c|c|c|}
\hline Birth Year & Age & Group & $\mathrm{n}$ & $\frac{\%}{0}$ \\
\hline \multirow[t]{3}{*}{1977} & 17 & Blocked & 1 & 11 \\
\hline & & Serial & 2 & 25 \\
\hline & & Total & 3 & 17 \\
\hline \multirow[t]{3}{*}{1978} & 16 & Blocked & 2 & 22 \\
\hline & & Serial & 1 & 13 \\
\hline & & Total & 3 & 17 \\
\hline \multirow[t]{3}{*}{1979} & 15 & Blocked & 0 & 0 \\
\hline & & Serial & 4 & 50 \\
\hline & & Total & 4 & 24 \\
\hline \multirow[t]{3}{*}{1980} & 14 & Blocked & 6 & 67 \\
\hline & & Serial & 1 & 13 \\
\hline & & Total & 7 & 41 \\
\hline
\end{tabular}

and seven 14 year olds, six blocked and one serial. The 14year-old group made up 68\% of the blocked group, $13 \%$ of the serial group and $41 \%$ of the all the subjects.

The responses to total soccer experience were grouped into intervals of 4 years: 1 to 4 years, 5 to 8 years, and 9 to 12 years. None of the subjects had less than 5 years experience. Five subjects had 5 to 8 years experience, two 
in the blocked and three in the serial group; 12 subjects had 9 to 12 years experience, seven in the blocked and five in the serial group. Those subjects with 9 to 12 years experience comprised $71 \%$ of the subjects, as depicted in Table 3 .

Table 3

Total Soccer Experience Frequency and Percentage of Subjects by Group and Total Frequency and Percentage

\begin{tabular}{cccc}
\hline Experience & Group & n & \% \\
\hline \multirow{2}{*}{5 to 8 years } & Blocked & 2 & 22 \\
& $\begin{array}{c}\text { Serial } \\
\text { Total }\end{array}$ & 3 & 38 \\
\hline \multirow{2}{*}{9 to 12 years } & Blocked & 5 & 29 \\
\hline & Serial & 5 & 78 \\
& Total & 12 & 63 \\
\hline
\end{tabular}

Players with no previous varsity soccer experience comprised $59 \%$ of the subjects as noted in Table 4 . Ten subjects reported no varsity experience, six in the blocked and four in the serial group; two subjects reported one year experience, both were in the serial group; three subjects reported two years experience, two in the blocked and one in the serial group; and two subjects reported three years experience, one in the blocked and one in the serial group. 
Table 4

Varsity Soccer Experience and Percentage of Subjects by Group and Total Frequency and Percentage

\begin{tabular}{cccc}
\hline Experience & Group & n & $\%$ \\
\hline None & Blocked & 6 & 67 \\
& Serial & 4 & 50 \\
\cline { 2 - 4 } & Total & 10 & 59 \\
\hline \multirow{2}{*}{1 year } & Blocked & 0 & 0 \\
& Serial & 2 & 25 \\
\cline { 2 - 4 } 2 years & Total & 2 & 12 \\
\hline & Blocked & 2 & 22 \\
& Serial & 1 & 13 \\
\hline \multirow{2}{*}{3 years } & Total & 3 & 18 \\
& Blocked & 1 & 11 \\
& Serial & 1 & 12 \\
\hline
\end{tabular}

Thirteen subjects reported no junior varsity

experience, comprising $77 \%$ of the subjects, as indicated in Table 5. The blocked group was made up completely of the subjects with no junior varsity experience. Fifty-percent of the subjects in the serial group had no junior varsity; the other $50 \%$ had one year junior varsity experience. 
Table 5

Junior Varsity Experience Freguency and Percentage of

Subjects by Group and Total Frequency and Percentage

\begin{tabular}{cccc}
\hline Experience & Group & $\mathrm{n}$ & \% \\
\hline \multirow{2}{*}{ None } & Blocked & 9 & 100 \\
& Serial & 4 & 50 \\
\cline { 2 - 4 } & Total & 4 & 77 \\
\hline \multirow{2}{*}{1 year } & Blocked & 0 & 0 \\
& Serial & 4 & 50 \\
& Total & 13 & 24 \\
\hline
\end{tabular}

Fourteen of the subjects or $82 \%$ expected to play on the varsity team this year. Eight were in the blocked and six were in the serial groups. These data are depicted in Table 6. Three subjects expected to play junior varsity, one in the blocked and two in the serial group.

Table 6

Varsity Experience Frequency and Percentage of subjects by Group and Total Frequency and Percentage

\begin{tabular}{cccc}
\hline Team & Group & $\mathrm{n}$ & \% \\
\hline Varsity & Blocked & 8 & 89 \\
& Serial & 6 & 75 \\
\cline { 3 - 4 } & Total & 14 & 82 \\
\hline \multirow{2}{*}{ Jr. Varsity } & Blocked & 1 & 11 \\
& Serial & 2 & 25 \\
\hline & Total & 3 & 18 \\
\hline
\end{tabular}


There was one goalie, five defenders, seven midfielders, and four forwards tested. Midfielders can be classified as either primarily offensive or defensive players or a combination, depending upon the skill level and coaching strategy. The serial group had 50\% specialized defensive players, compared to $22 \%$ in the blocked group. These data are depicted in Table 7 . Having more defensive specialists could be a detriment when the skill being tested is primarily an offensive skill.

Table 7

Position Normally Played Erequency and Percentage of Subjects by Group and Total Frequency and Percentage

\begin{tabular}{cccc}
\hline Position & Group & n & \% \\
\hline Goalie & Blocked & 0 & 0 \\
& Serial & 1 & 13 \\
\cline { 2 - 4 } & Total & 1 & 6 \\
\hline \multirow{2}{*}{ Defender } & Blocked & 2 & 22 \\
& Serial & 3 & 38 \\
\cline { 2 - 4 } & Total & 5 & 29 \\
\hline \multirow{2}{*}{ Midfielder } & Blocked & 5 & 56 \\
& Serial & 2 & 25 \\
\cline { 2 - 4 } & Total & 7 & 41 \\
\hline \multirow{2}{*}{ Forward } & Blocked & 2 & 22 \\
& Serial & 2 & 25 \\
\hline & Total & 4 & 24 \\
& &
\end{tabular}


Sixteen subjects or $94 \%$ were right-foot dominant. One player was left-foot dominant.

Sixteen of the 17 subjects had successfully scored a goal in a game. One subject had never scored a goal in a game, she was in the blocked group. The subject that had never scored before was a midfielder. The goalie had scored a goal in a game.

The groupings for the number of goals scored was done in five-goal intervals: None, 1 to 5,6 to 10,11 to 15 and 16 or more. Two subjects had not scored in the past two seasons. Five subjects reported scoring 1 to 5 goals, none scored 6 to 10 goals, two scored 11 to 15 goals, and nine scored 16 or more goals. These data are reported in Table 8 .

Analyses of Blocked and Serial Groups

All statistical tests were conducted using the mean trial block shooting accuracy scores, and are presented in Table 9. Mean trial block scores were calculated based on the day of the trials, including pretest trial block, acquisition trial block 1, acquisition trial block 2, acquisition trial block 3 , retention trial block and transfer trial block. The analyses are presented in the following section under acquisition, retention and transfer phases. The SPSS-PC+ statistical software, version 3.0, was 
used to analyze acquisition, retention, and transfer shooting accuracy data (Norusis, 1988).

Table 8

Goals Scored in the Past Two Seasons Frequency and

Percentage of Subjects by Group and Total Frequency and Percentage

\begin{tabular}{cccc}
\hline Goals scored & Group & $\mathrm{n}$ & \% \\
\hline \multirow{2}{*}{ None } & Blocked & 1 & 11 \\
& Serial & 1 & 13 \\
\cline { 3 - 4 } & Total & 2 & 12 \\
\hline \multirow{2}{*}{1 to 5} & Blocked & 2 & 22 \\
& Serial & 3 & 38 \\
\hline \multirow{2}{*}{11 to 15} & Total & 5 & 29 \\
\hline & Blocked & 0 & 0 \\
& Serial & 2 & 25 \\
\hline \multirow{2}{*}{16 or more } & Total & 2 & 12 \\
& Blocked & 6 & 67 \\
& Serial & 3 & 38 \\
\hline & Total & 9 & 53 \\
\hline
\end{tabular}


Table 9

Means by Trial Blocks and Acquisition Contextual

Interference Group

\begin{tabular}{cccc}
\hline Trial Block & Blocked & Serial & Combined \\
\hline $\begin{array}{c}\text { Pretest Trial Block } \\
\text { Day I }\end{array}$ & 2.93 & 3.79 & 3.36 \\
\hline $\begin{array}{c}\text { Acquisition Trial Block } 1 \\
\text { Day I }\end{array}$ & 2.32 & 2.32 & 2.32 \\
\hline $\begin{array}{c}\text { Acquisition Trial Block } 2 \\
\text { Day 2 }\end{array}$ & 2.93 & 2.78 & 2.86 \\
\hline $\begin{array}{c}\text { Acquisition Trial Block } 3 \\
\text { Day 3 }\end{array}$ & 2.94 & 2.75 & 2.85 \\
\hline $\begin{array}{c}\text { Retention Trial Block } \\
\text { Day 4 }\end{array}$ & 2.47 & 3.04 & 2.74 \\
\hline $\begin{array}{c}\text { Transfer Trial Block } \\
\text { Day 4 }\end{array}$ & 2.31 & 3.39 & 2.82 \\
\hline
\end{tabular}

\section{Acquisition}

A 2 (Acquisition Groups) X 3 (Acquisition Trial Blocks) ANOVA with repeated measures on the second factor was conducted on the acquisition data. Acquisition group did not significantly impact shooting accuracy $F(1,15)=.89$, $p>.05$. The null hypothesis that acquisition contextual interference would not affect shooting accuracy in acquisition was accepted. Trial block had a significant effect on shooting accuracy $F(2,30)=4.93, p<.05$. These results are displayed in Figure 4 . When the scores were collapsed over blocked and serial groups, it was found that shooting accuracy for trial block $1(M=2.32)$ was 


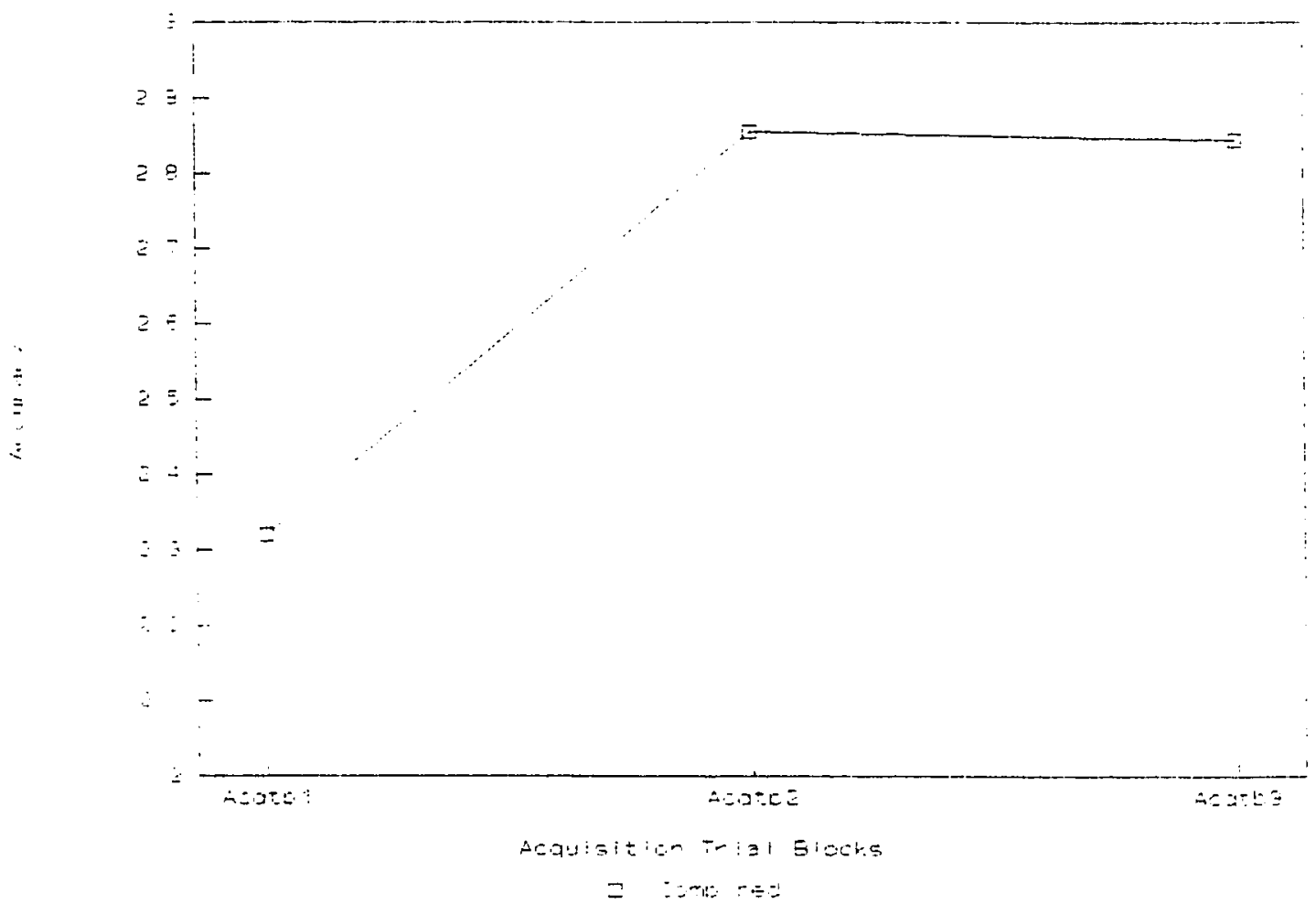

Figure 4

Mean Scores Collapsed Over Blocked and Serial Groups During Acquisition Trial Blocks 
significantly less accurate than trial block 2 ( $M=2.86$ )

and trial block $3(M=2.85)$. The null hypothesis that trial block would not affect shooting accuracy in acquisition was rejected.

The interaction of acquisition group and trial block was not statistically significant $F(2,30)=.13, p>.05$. The null hypothesis that acquisition contextual interference and trial block would not affect shooting accuracy in acquisition was accepted.

\section{Retention and Transfer}

Two separate one way ANCOVA tests, one for retention and one for transfer, were conducted using group as the independent variable and shooting accuracy as the dependent variable. The covariate for the analysis was the trial block mean for the three pretest trials. In the retention analysis, no significant group effect was found $F(1,14)=1.72, p>.05$. The null hypothesis that acquisition contextual interference would not affect shooting accuracy in retention was accepted. In the transfer analysis a significant group effect was found $F(1,14)=10.89, p<.05$. The inspection of the means supported that the serial group $(M=3.40)$ had significantly greater shooting accuracy than the blocked group ( $M=2.31$ ). The null hypothesis that acquisition contextual interference would not affect shooting accuracy in transfer was rejected. 
Summary of the Results

The only significant difference between groups was found in transfer shooting accuracy scores. The serial group was significantly more accurate than the blocked group. Caution should be taken when interpreting this significant effect because of the practical difference between the mean scores for the two groups ( $M$ (serial) = 3.40 and $M$ (blocked) $=2.31$ ). In other words, one might suggest that both groups had moderate levels of shooting accuracy since the range of possible scores was 0 to 6 and these groups performed in the middle of the range. 


\section{Chapter 5}

\section{Discussion}

The application of theory to practice is a constant struggle for researchers and practitioners alike. Significant results need to be obtained in laboratory studies before field tests can be conducted to determine if ecological validity can be established (Locke, 1990). Significant results in laboratory studies have inspired field studies on contextual interference.

The purpose of this study was to expand upon the concept of contextual interference provided by Lee and Magill (1983), and tested by Goode and Magill (1986). Goode and Magill (1986) tested Lee and Magill's (1983) hypothesis in a field study using three badminton serves. In the Lee and Magill (1983) and Goode and Magill (1986) studies, blocked, serial, and random acquisition groups using similar motor tasks were tested for acquisition and retention of skills. In addition, Lee and Magill tested for transfer of skills.

This study focused on two groups, blocked and serial in a field study. The random group was deleted from the main study because of the time problem involved in testing the group during the pilot study. The serial group was added because in 1983, Lee and Magill found that the random and serial groups produced significant results when compared to 
a blocked group. In the present study, serial practice order did not exhibit the time problems associated with a random practice order.

Pretest

Collapsed across the three pretest trials, the serial group scored higher (3.79) than the blocked group (2.93). No explanations can be offered for the differences between block and serial pretest scores. However, the combined mean scores for both groups (3.36) was the highest combined mean score for the study (Table 9).

A possible explanation for this difference is that the pretest distance used was familiar for experienced soccer players. It is the penalty spot. A penalty shot is taken from the penalty spot, 12 yards directly in front of the goal, and is the only consistent shooting distance in soccer. A penalty shot is taken when a major infraction occurs near the goal. The player is allowed to place the soccer ball on the penalty spot and is allowed to take time to prepare to shoot. The penalty shot is also used to determine a winner if the game is tied at the end of the overtime period. Many soccer games have been decided from a team's accuracy at shooting penalty shots. Because of the importance of penalty shots, most experienced players practice the shot and become proficient at scoring in the outer corners of the goal. This was where the 5 and 6 -point 
scoring areas where located on the target goal used in this study.

Even though the pretest trials used a moving soccer ball and not a stationary soccer ball from the penalty spot, both motor patterns may be considered in the same movement class (Magill \& Hall, 1990). The motion of the ball was the only difference in skills. Several studies (Lee, 1988; Magill \& Hall, 1990; Shea \& Zimny, 1988) have explained that a memorization process occurs when subjects practice in a blocked format. Other studies have explained that experienced athletes generally have a broader knowledge base (Del Rey et al., 1987; and Del Rey et al. 1982) and can influence processing that benefits memory and transfer. It is possible that the previously learned motor pattern of shooting penalty shots may have transferred to the pretest trials.

\section{Acquisition}

Only three studies have been found which used a serial acquisition group and a similar motor pattern skill to test the contextual interference hypothesis (Lee \& Magill, 1983; Goode \& Magill, 1986). Conflicting acquisition findings have been provided. Lee and Magill found a significant difference between blocked and serial groups during acquisition; whereas a similar difference between blocked 
and serial groups was not produced during acquisition by Goode and Magill (1986).

In the present study, significant differences were found in acquisition between trial blocks, but no differences were found between blocked and serial groups. The findings of the present study resemble Goode and Magill's (1986) findings during acquisition. Goode and Magill offered a possible explanation for the difference between acquisition findings in studies. The scoring system used by Lee and Magill was more sensitive than in the present study because the dependent measure was time measured in milliseconds.

The scoring used in this study was similar to Goode and Magill (1986) in that a zero was possible when the subject missed the target. Goode and Magill (1986) found that "Early in acquisition the subjects scored a zero on more than half of the trials." In this study the serial group scored a zero on $14 \frac{\circ}{6}, 8 \%$ and $11 \frac{\circ}{6}$ of the shots taken during acquisition trial blocks 1,2 and 3 , respectively. The blocked group received a zero on $20 \%, 12 \%$, and $17 \%$ during acquisition trial blocks 1,2 , and 3 , respectively.

The difference in scoring systems between Goode and Magill and this study is that they used a target area that generated points of $5,4,3,2$, and 1 in a circle or bullseye format where the center received the higher point 
values. If the shuttle cock landed outside the target area or an illegal serve was performed, a zero was awarded for the trial.

In this study, the scoring target was different. Two points were awarded for shooting to the center of the target. Shots toward the edges of the target were awarded greater point values as well as lower point values (Appendix A). Unlike the bulls-eye, the further from the center the lower the point scores and lower the accuracy. This study placed emphasis on shooting at an area that increases the probability of scoring a goal when a goalkeeper is protecting the goal.

The scoring target may not have been sensitive to a subject's shooting accuracy while shooting at the target. More specifically, if a subject attempted a 6-point shot into the target area and was off by 4 inches or more (either low, to the inside, or low and to the inside) a score of 5 , 4 or 3 was awarded. If the subject was off by four inches or more, either high or to the outside, the subject received a zero. If the shot went low and wide or only four inches wide and hit the goal posts, the subject received one point.

On the other hand, if the subject attempted to shoot at the middle of the goal and she was off target she would not be penalized. If she shot wide in either direction, she would actually be rewarded. A shot to either side of the 2- 
point area or center of the goal could award her either 3 or 4 points. The only consideration was to keep the ball low. If the shot was slightly high and hit the cross bar, one point was scored. If she missed high completely, zero points were scored.

As explained earlier, if the subject attempted to shoot at the 6-point area and missed, she may have scored from 0 to 5 points, yet if the subject attempted to shoot at the 2point area and missed she may have been rewarded with 3 or 4 points, or may have received 1 or 0 points if she shot high. Both blocked and serial received the same mean score 2.32 during acquisition block 1 , but as is indicated in Table 10 a varied difference in scoring distribution occurred. The blocked group scored more 5 and 6 -point scores as well as more 0 and 1 -point scores than the serial group. In comparison the blocked group scored less of its points in the 2,3 and 4 point range compared to the serial group, yet both groups had the same mean scores. 
Table 10

Collapsed Acquisition Trial Block 1 Score Distribution of Placement Scores and Percentages by Point Values

\begin{tabular}{ccccccccc}
\hline Group & 0 & 1 & 2 & 3 & 4 & 5 & 6 & Trials \\
\hline Blocked & 22 & 9 & 32 & 20 & 11 & 10 & 4 & 108 \\
$\%$ & $20 \%$ & $8 \%$ & $30 \%$ & $19 \%$ & $10 \%$ & $9 \%$ & $4 \%$ & \\
\cline { 2 - 8 } Serial & 13 & 8 & 35 & 27 & 11 & 1 & 1 & 96 \\
$\%$ & $14 \%$ & $8 \%$ & $35 \%$ & $28 \%$ & $11 \%$ & $1 \%$ & $1 \%$ & \\
\hline
\end{tabular}

During acquisition the number of times the subjects in the blocked group scored 2 points decreased and the 5 points increased through acquisition trial blocks Table 11. The serial group decreased its shots to the 3 -point areas and increased the number of shots to the 4, 5 and 6-point target areas as is indicated in Table 12. This was a positive outcome because the target goal was set up to encourage such shot selection. The purpose of having a 1-point area just wide of the goal but only 4 feet high was to encourage a low shot to the corner of the goal. If a goalkeeper did try and save the shot and successfully hit the ball, then the ball might stay in play and allow for a follow up shot by another player. Despite the lack of sensitivity of the scoring system used, it is believed that the system was representative of shooting accuracy needed for a soccer game. 
Table 11

Blocked Group Placement Scores on the Target Goal by Acquisition Trial Block.

\begin{tabular}{ccccccccc}
\hline Trial Block & 0 & 1 & 2 & 3 & 4 & 5 & 6 & Total \\
\hline Acq 1 & 22 & 9 & 32 & 20 & 11 & 10 & 4 & 108 \\
Acq 2 & 13 & 13 & 21 & 21 & 13 & 16 & 11 & 108 \\
Acq 3 & 18 & 11 & 14 & 21 & 13 & 23 & 8 & 108 \\
\hline
\end{tabular}

Table 12

Serial Group Placement Scores on the Target Goal by Acquisition Trial Block.

\begin{tabular}{ccccccccc}
\hline Trial Block & 0 & 1 & 2 & 3 & 4 & 5 & 6 & Total \\
\hline Acq 1 & 13 & 8 & 35 & 27 & 11 & 1 & 1 & 96 \\
Acq 2 & 8 & 18 & 21 & 13 & 14 & 20 & 2 & 96 \\
Acq 3 & 11 & 8 & 32 & 11 & 16 & 13 & 5 & 96 \\
\hline
\end{tabular}

Retention

In the present study the serial group performed better than the blocked group although not at a statistically significant level. The result approached statistical significance $(F(1,15)=.060, p>.05)$. The retention findings from other studies have varied considerably when serial and blocked groups were compared. Lee and Magill (1983) found that serial group performed significantly better than the blocked group during retention. Bortoli et al. (1992) and Goode and Magill (1986) did not find a 
significant difference between serial and blocked groups. Even though Goode and Magill (1986) and the present study did not find a significant difference, the serial group was more accurate than the blocked group, more closely resembling a contextual interference effect.

\section{Transfer}

The random transfer context used in the present experiment simulated a changing context from trial to trial as is found in a game situation. The ANCOVA on transfer shooting accuracy revealed a significant difference between serial and blocked groups. The serial group had higher shooting accuracy than the blocked group. Serial type of processing produced a contextual interference effect.

Lee and Magill (1983) also found a significant difference between the serial and blocked groups on transfer scores. Lee and Magill (1983) suggested the reason significant differences were found, in high contextual interference (random and serial) practice schedules compared to low contextual interference (blocked) practice schedules, was the result of the performance of different motor tasks between trials (serial format), and not the unpredictability of motor tasks (random format) between trials.

One of the transfer tests conducted by Bortoli et al. (1992) revealed that the random and serial groups were significantly different compared to the blocked and serial 
with high interference groups on the long transfer test for serving. A possible explanation given for the lack of significance on other transfer tests was that the transfer tests were not difficult enough, and subjects may have reached a high level of proficiency during each of the practice schedules.

Goode and Magill (1986) did not find any significant differences between the serial group and the blocked or random groups. No possible explanation for the lack of significance for the serial group was given because they limited their discussion to the significance found between random and blocked groups in the field study. Summary

The purpose of this study was to test the acquisition contextual interference effect of a serial practice schedule compared to a blocked practice schedule on acquisition, retention and transfer. Several studies in both laboratory (Lee \& Magill, 1983; Shea \& Morgan, 1979; Shea \& Zimny, 1983) and field (Goode \& Magill, 1986; Wrisberg \& Liu, 1991) settings have produced a contextual interference effect when random and blocked practice schedules have been used. The literature regarding serial practice schedules has produced conflicting results (Bortoli et al., 1992; French et al., 1990; Goode \& Magill, 1986; Lee \& Magill, 1983) that warrant further investigation. Five null hypotheses were made for 
the purpose of the 'study. Two were rejected, (a) trial block affected shooting accuracy in acquisition and (b) acquisition contextual interference had an impact on transfer.

The serial group performed significantly better than the blocked group even though the serial group was comprised of more specialized defensive players (51\%) compared to the blocked group (22\%), in the transfer test using a skill that is primarily offensive. It may have been anticipated that defensive players would not perform as well as offensive players on offensive skills. It is important not to stereotype players' skills based upon the position normally played because they may possess just as good and possibly better skills than those of a player in another position. Future Recommendations

The design of the target has some inherent problems which were recognized in the study. The target design was constructed to resemble a game situation. The further a shot gets from the middle of the target the greater the risk of receiving a zero or a low score. Soccer players need to shoot towards the corners of the goal to increase the probability of scoring goals. The data in Tables 11 and 12 , revealed that subjects began to score fewer points in the middle of the goal and more towards the outer edges of the target as the experiment continued. 
A recommendation for future study is to question the subject as to where he or she is aiming and compare the actual score to the intention. This would allow researchers to compare intentions versus results. A subject may be shooting towards 5 and 6 -point areas and receive zero and 1 points yet may be becoming a more productive game shooter than the subject who is shooting at the middle of the target and scoring 2,3 or 4 because she shoots towards where a goalkeeper is positioned.

One of the considerations in the design of this study was the feasibility for a coach or teacher to replicate the serial practice order in a coaching situation. A consideration in the practice order (serial or random) for future studies is whether a coach has numerous subjects that are required to perform the task. A coach who is required to give each subject directions individually in a random practice order, as to the intended target area or procedure, cannot be expected to coach a large number of subjects during the same practice session. On the other hand, if serial practice order is used, a coach can give the directions to the group and can supervise a larger practice group than when random format is used.

Many contextual interference studies that have used random practice trials allowed for one-on-one situations to ensure the proper execution of the task or did not have 
stringent time constraints. Team sports require coaches to have many subjects perform the desired practice task, and a coach cannot be consumed in administering a random practice schedule to each player because the focus is on the practice schedule and not on the practice.

Another consideration is that the coach or teacher needs to be able to teach during the practice session. The coach or teacher in youth sports is usually only one person and cannot be rigid and focus all of the attention on assigning a random order during the practice session. The coach or teacher's time needs to be used as efficiently as possible. The coach or teacher needs a good learning paradigm that is simple yet effective, and must be able to point out the teaching objectives, provide knowledge of results, or encouragement during the session.

If a subject needs one-on-one directions to perform tasks in a random format every time a skill is going to be performed, e.g., throwing a ball to point $A$, then $C$, then $B$, then the coach should consider using the serial format for time efficiency. If a subject is the recipient, e.g., the baseball or softball outfielder who must chase down a ball hit to her, then a random format is more appropriate.

Gentile (1972) describes two very important tasks that a teacher must perform in an open environment to enhance learning: first, create a specific environmental problem, 
and second, establish an adequate motivation level. The present study evaluated both of these concerns in the design of the main study.

First, the specific environmental problem was developed by creating a target goal that encouraged shooting toward high probability score areas. Second, the serial practice schedule and shooting a moving soccer ball (open skill) were used to maintain an appropriate learning motivation level. The pilot study offered direction for the main study in both areas. Gentile's tasks need to be considered in future field study to increase the probability of replicating laboratory results.

More field studies need to be conducted that are more applicable and appropriate for coaches and teachers. When more field studies are done, then hopefully educational books will begin to incorporate contextual interference designs for coaching and teaching. 


\section{References}

Battig, W. F. (1979). The flexibility of human memory. In I. S. Cermak \& F. I. M. Craik (Eds.), Levels of processing and human memory. Hillsdale, N.J.: Erlbaum.

Bortoli, L., Robazza, C., Durigon, V., \& Carra, C. (1992). Effects of contextual interference on learning technical sports skills. Perceptual and Motor skills, 75, 555-562.

Browning C. K., \& Schack F.K. (1990). Effects of instruction on throwing performances of sixth grade girls. Physical Educator, $\underline{47}, 144-152$.

Burton, A. W., \& Welch, B. A. (1990). Dribbling performance in first-grade children: effect of ball and hand size and ball-size preferences. Physical Educator, 47, 4851 .

Del Rey, P., Whitehurst, M., Wughalter, E., \& Barnwell, J. (1983). Contextual interference and experience in acquisition and transfer. Perceptual and Motor Skilis, 57, 241-242.

Del Rey, P., Wughalter, E., \& Carnes, M. (1987). Level of expertise, interpolated activity and contextual interference effects on memory and transfer. Perceptual and Motor Skills, 64, 275-284.

Del Rey, P., Wughalter, E. H., \& Whitehurst, M. (1982). The effects of contextual interference on females with varied experience in open sport skills. Research Quarterly For Exercise and Sport, 53(2), 108-115.

Goode, S., \& Magill, R. A. (1986). Contextual interference effects in learning three badminton serves. Research Quarterly For Exercise and Sport, 57(4), 308-314.

Dunham Jr., P., Lemke, M., \& Moran, P. (1991). Effect of equal and random amounts of varied practice on transfer task performance. Perceptual and Motor Skills, 73, 673674 .

French, K., Rink, J., \& Werner, P. (1990). Effects of contextual interference on retention of three volleyball skills. Perceptual and Motor Skills, 71, 179-186. 
Gentile, A. M. (1972). A working model of skill acquisition with application to teaching. Quest, XVII, 3-23.

Gusthart, J. L., \& Kelly, I. W. (1991). Teachers' motor skills in volleyball and students' learning. Perceptual and Motor Skills, 72, 795-801.

Heuer, H. (1988). The Laboratory and the world outside. In O. G. Meijer \& K. Roth (Eds.), Complex Movement Behavior: The motor-action controversy. (pp. 405-417). North-Holland: Elsevier Science Publishers B.V.

Hopper, C., Guthrie, G. D. , \& Kelly, T. (1991). Self-concept and skill development in youth soccer players. Perceptual and Motor Skills, 72, 275-285.

Hughes, C. (1980). The football Association Coaching Book of Soccer Tactics and Skills. London, England: British Broadcasting Corporation and Queen Anne Press.

Ingels, N. B. (1975) . Coaching Youth Soccer. Monterey, California: Page-Ficklin Publishing.

Industry Survey (1987). Sporting Goods Sales. Sacramento: Government Publication.

Jacoby, L. L. (1978). On interpreting the effects of repetition: solving a problem versus remembering a solution. Journal of Verbal Learning and Verbal Behavior. 17, 649-667.

Kirk, D. (1989). The Orthodoxy in RT-PE and the research/practice gap: A critique and an alternative view. Journal of Teaching in Physical Education, 8 , $123-130$

Lee T. D., \& Magill, R. A. (1983). The locus of contextual interference in motor-skill acquisition. Journal of Experimental Psychology: Learning, Memory \& Cognition. 2, 730-746.

Lee, T. D., Wulf, G. \& Schmidt, R. A. (1992). Contextual interference in motor learning: dissociated Effects due to the nature of task variations. The Quarterly Journal of Experimental Psychology. 44A(4), 627-644.

Locke, L. F. (1990). Why motor learning is ignored: a case of ducks, naughty theories, and unrequited love. Quest. 42, 134-142. 
Magill, R. A. (1990). Motor learning is meaningful for physical educators. Quest. 42, 126-133.

Magill, R. A., \& Hall, K. G. (1990). A review of the contextual interference effect in motor skill acquisition. Human Movement Science, 2, 241-289.

Norusis, M. J. (1988). SPSS/PC+ V3.0 Update manual for the IBM PC/XT/AT and PS/2. Chicago: SPSS

O'Shea, G. P. (1986). Youth Soccer: The Amateur Coach. Lexington, Massachusetts: The Stephen Greene Press.

Shea, J. B., \& Morgan, R. L. (1979). Contextual interference effects on the acquisition, retention, and transfer of a motor skill. Journal of Experimental Psychology: Human Learning and Memory. 5, 179-187.

Shea, J. B. \& Titzer, R. C. (1993). The influence of reminder trials on contextual interference effects. Journal of Motor Behavior. 4, 264-274.

Shea, J. B. \& Zimny, S. T. (1988). Knowledge incorporation in motor representation. In O. G. Meijer \& $\mathrm{K}$. Roth (Eds.), Complex Movement Behavior: The motor-action controversy. (pp. 405-417). North-Holland: Elsevier Science Publishers B.V.

Shea, J. B. \& Zimny, S. T. (1983). Context effects in memory and learning movement information. In R. A. Magill (Ed.), Memory and Control of Action. (pp. 345-367). North-Holland Publish Company.

Singer, R. N. (1990). Motor learning research: meaningful for physical educations or a waste of time? Quest. 42 , 114-125.

Vogelsinger, H. (1983). All-Star Soccer Schools and Vogel singer Soccer Academy.

Welford, A. T. (1988). Acquiring skill: some experiences. Journal of Motor Behavior. 20, 458-461.

Whitehurst, M., \& Del Rey, P. (1983). Effects of contextual interference, task difficulty, and levels of processing on pursuit tracking. Perceptual and Motor skilis, 57, $619-628$. 
Wood, C. A., \& Ging, C. A. (1991). The role of interference and task similarity on the acquisition, retention, and transfer of simple motor skilis. Research Quarterly for Exercise and sport. $\underline{62}(1), 18-26$.

Wright, D. L., Li, Y., \& Whitacre, C. (1992). The contribution elaborative processing to the contextual interference effect. Research Quarterly for Exercise and Sport. 63(1), 30-37.

Wrisberg, C. A., \& Liu, z. (1991). The effect of contextual variety on the practice, retention, and transfer of an applied motor skill. Research Quarterly for Exercise and Sport, 62 (4), 406-412.

Wulf, G. \& Lee, T. D. (1993). Contextual interference in movements of the same class: Differential effects on program and parameter learning. Journal of Motor Behavior. 4, 254-263. 
Appendix A

Target Goal

\begin{tabular}{|c|c|c|c|c|c|c|c|}
\hline & 6 & 4 & 2 & 2 & 4 & 6 & \\
\hline 1 & 5 & 3 & 2 & 2 & 3 & 5 & 1 \\
\hline
\end{tabular}

The target goal is comprised of a regulation size soccer goal and two 4 foot high by 3 foot wide additions, located on the sides of soccer goal. The target goal has been subdivided into sections and a point value has been assigned to each section.

\begin{tabular}{||c|c|c|c|c|c||}
\hline 6 & 4 & 2 & 2 & 4 & 6 \\
\hline 5 & 3 & 2 & 2 & 3 & 5 \\
\hline \\
\hline
\end{tabular}

The inside of the soccer goal is divided into 4 foot squares and each square is assigned a point value ranging from 2 to 6 points. The center of the goal is usually protected by the goalkeeper, the farther the shot is from the center the greater the probability to score a goal. 
Appendix A

(Continued)

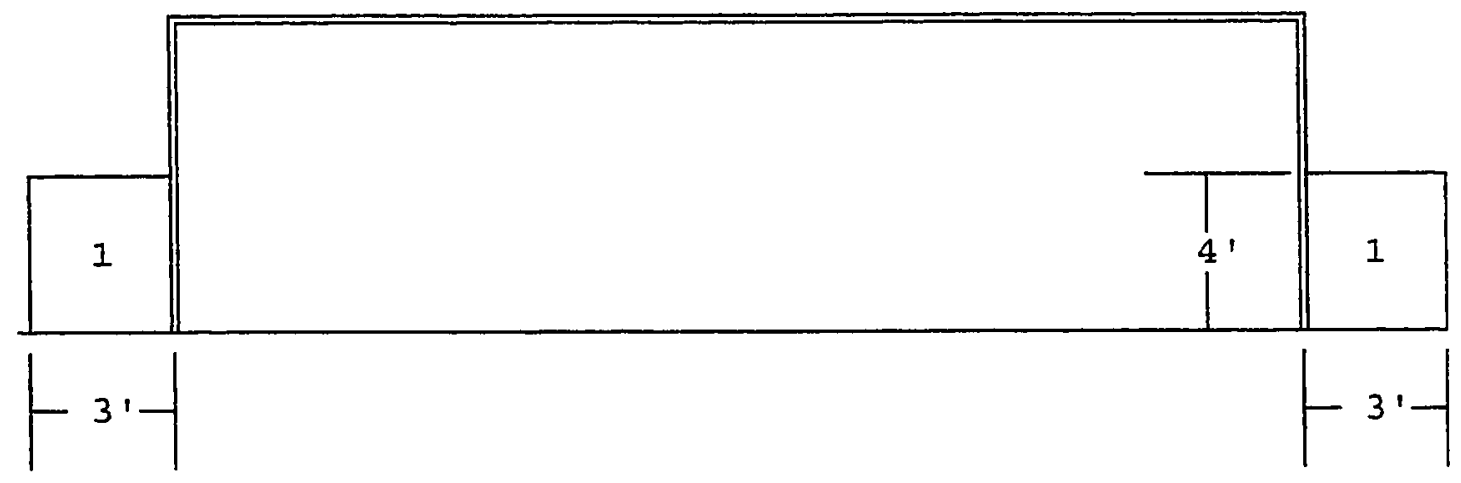

An additional 4 foot high by 3 foot wide area located outside of the soccer goal has been added to comprise the target goal. If the soccer ball hits any of these areas, regardless of how the ball rebounds, the subject will be awarded one point.

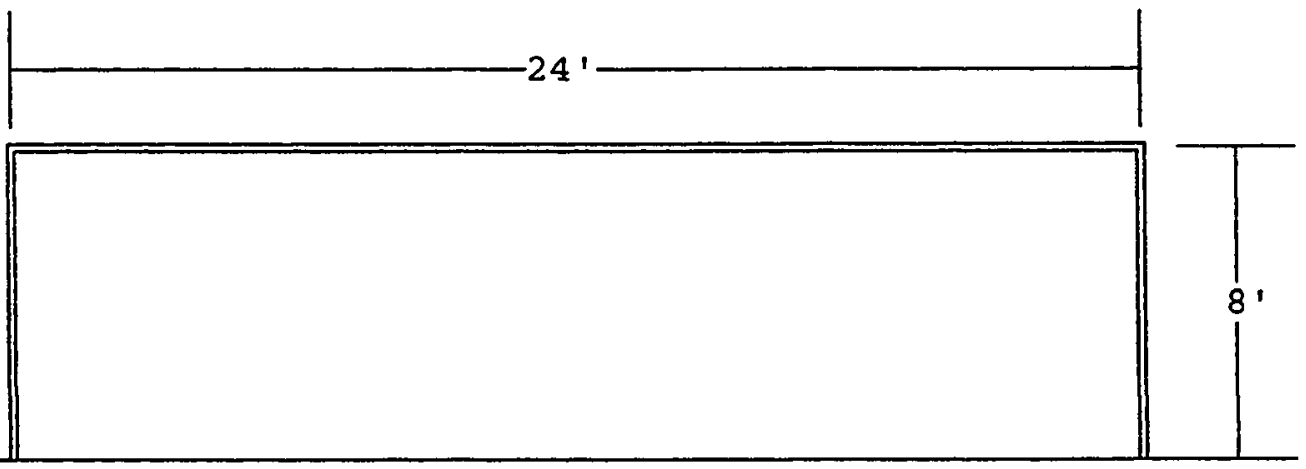

The perimeter of the soccer goal is comprised of two 8 foot vertical flat bars and one 24 foot horizontal flat bar. If a soccer ball hits one of the bars and the ball rebounds back into the playing field, the subject will be awarded one point. 
Appendix B

Acquisition and Retention Locations for Pilot Study

Normal markings on a soccer field and the locations of the acquisition and retention distances.

Goal

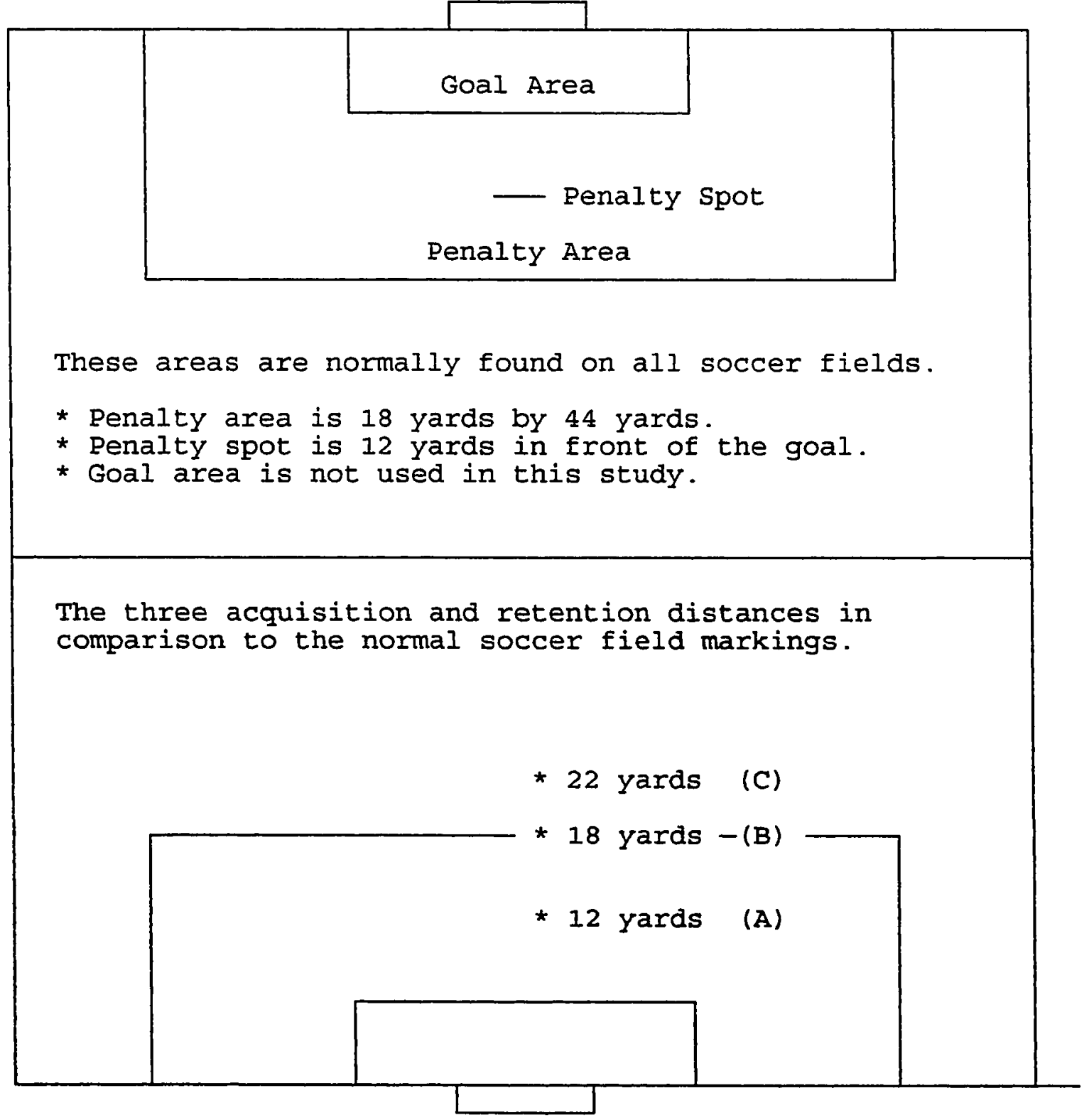


Appendix C

Consent Form for Pilot Study

My child or ward has been

asked to participate in a research study entitled Effects of Contextual Interference on Acquisition, Retention and Transfer of shooting a stationary soccer Ball, to be conducted for one week at a practice site determined by the team coach and CYSA commissioner under the direction of Edward H. Mattson. There are no anticipated risks. The subjects may benefit in shooting accuracy when kicking a stationary soccer ball.

The procedures have been explained to me and my child and we understand them. They are as follows: the purpose of this study is to determine the effects of contextual interference on the acquisition, retention and transfer of shooting a stationary soccer ball at different distances. The task involves kicking a soccer ball at a target goal as accurately as possible from different distances.

Experimental procedures will include four sessions. The first three sessions will consist of 27 trials per day and will last approximately one hour each day. The fourth session will be conducted on the fifth day and will consist of 15 trials and will last approximately 45 minutes. The first test will be preceded by an orientation to the field 
test in which all ṕrocedures will be explained, and an opportunity to ask questions and to warm up will be given. We understand that this consent and data may be withdrawn at any time without penalty. We have been given the right to ask questions, and our questions, if any have been answered to our satisfaction. We understand that there is no compensation for participation in this study. We understand the data will be reported in group form and individual data will be kept confidential.

If we have any complaints about the research we can contact Dr. Bryant, Ph.D, Chair of Human Performance Department, at (408) 924-3010. Questions or complaints about research, subjects' rights, or research-related injury may be presented to serena Stanford, Ph.D., Associate Academic Vice President for Graduate Studies and Research, at (408) 924-2480.

The signature of the parent or guardian on this document indicates approval for the child or ward to participate in the study and a statement that the child or ward is freely willing to participate.

\begin{tabular}{lll}
\hline Name of Child or Ward & \\
\hline Parent or Guardian Signature & $\frac{\text { Date }}{\text { Relation to Child or ward }}$ & Date
\end{tabular}


Appendix D

Descriptive Soccer Questionnaire for Pilot Study

Subject's name:

Birth year: $\quad 1979 \quad 1980$

Total years of soccer experience:

Position: Goalie Defender Midfielder Forward

Dominant kicking foot: Right Left

Do you normally take free kicks? Yes No

Subject number:

Group assigned: Blocked Random

Location of test site:

Day of test: 
Appendix E

Instructions for Pilot study

This research is designed to study the effects of two training methods, blocked and random, on acquisition, retention and transfer of shooting a stationary soccer ball from three distances: 12,18 and 22 yards.

Subjects will be evenly divided into two groups, blocked and random. There will be 3 acquisition test days and one day on which retention and transfer will be tested. One group will shoot at goal while the other group helps retrieve shots.

During acquisition subjects in each group will shoot 3 sets of 9 trials in a rotating order. After each set, the groups will switch. During retention and transfer each group will shoot 9 retention trials and 6 transfer trials. Both retention and transfer trials will be randomly assigned by the researcher.

Subjects are limited to use the inside or instep to kick the ball because these parts of the foot offer the greatest degree of accuracy. If another part of the foot is used such as the toe, a score of zero will be recorded for that trial. Subjects' goal is to be as accurate as possible with the type of kicks allowed, while shooting at the target goal. 
The target goal is comprised of a regulation soccer goal, 8 by 24 foot, the crossbar, the side poles and a 3 by 4 foot piece of wood adjacent to the side poles. The soccer goal is divided into 4 by 4 foot squares ranging from 2 to 6 points (a picture of the target goal will be available near the researcher). If the ball hits the rope and rebounds back to the field of play the lower point value will be awarded. The crossbar and side poles are worth "1" point each if the ball hits and rebounds into the field of play. The 3 by 4 foot piece of wood is worth "I" point if the ball hits it regardless of how the ball rebounds. Do you have any questions?

The goal of this study is to be as accurate as possible while trying to obtain the highest amount of points. 
Appendix F

Random Acquisition Trials Scoring Sheet for Pilot study

$$
A=12 \text { yds. } B=18 \text { yds. } \quad C=22 \text { yds }
$$

Subject

Set number 1

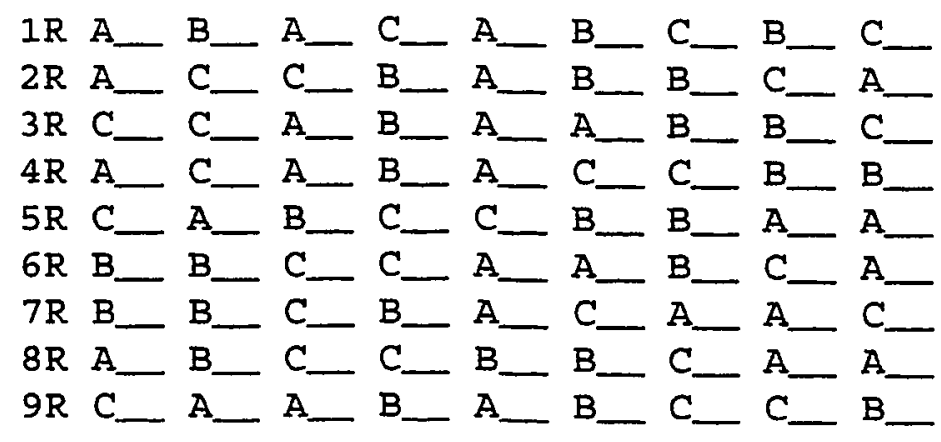

Set number 2

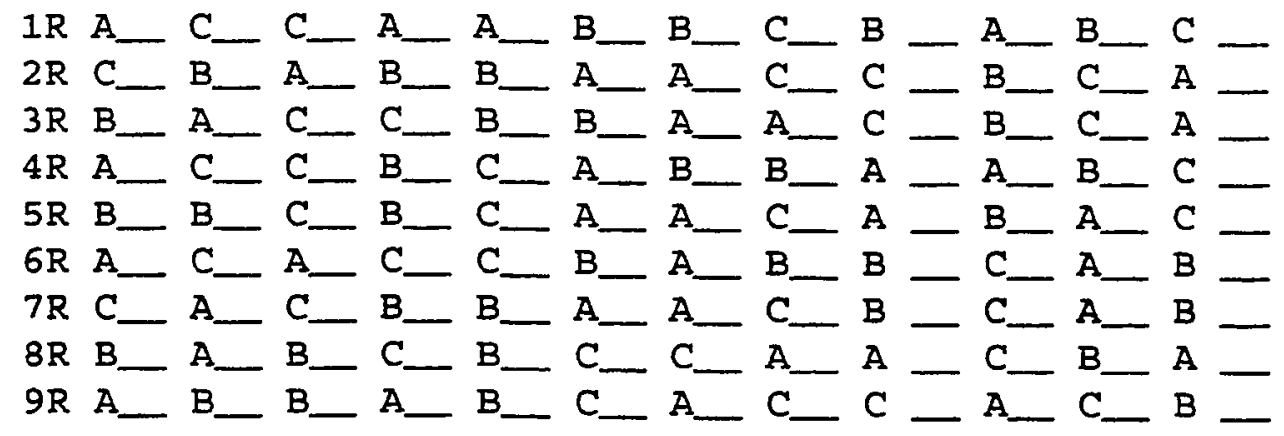

Set number 3

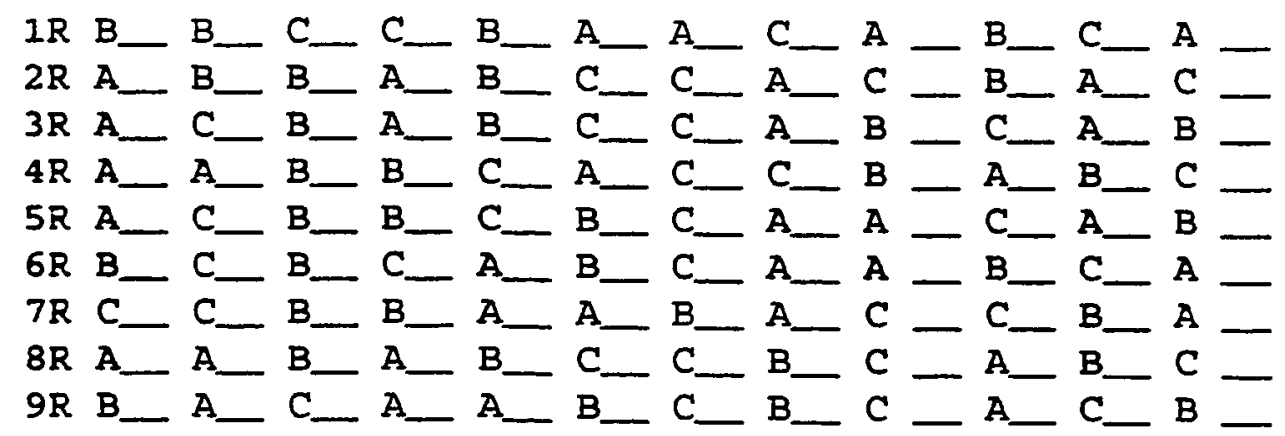




\section{Appendix G}

\section{Blocked Acquisition Trials Scoring sheet for pilot study}

$$
A=12 \text { yds. } \quad B=18 \text { yds. } \quad C=22 \text { yds } .
$$

Subject

Set number 1

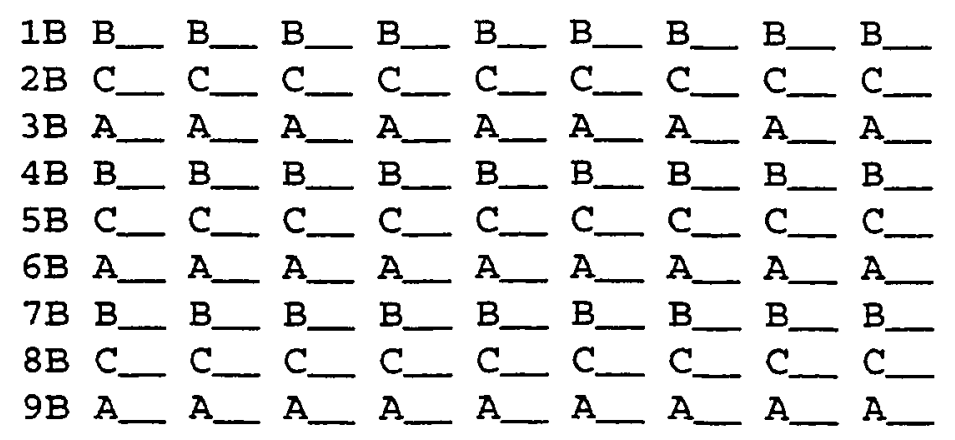

Set number 2

\begin{tabular}{|c|c|c|c|c|c|c|c|c|c|}
\hline LB & A & A & A. & & A & A & A & A & A \\
\hline B & $B_{-}$ & B. & B & & B_ & B_ & $B_{-}$ & B_ & B. \\
\hline B & C. & C_ & C. & & C & $C_{-}$ & C & C_ & C \\
\hline B & A & A & A & & A & A & A & A & A \\
\hline$B$ & B. & $B_{-}$ & B. & & $B_{-}$ & $B_{-}$ & B & $B_{-}$ & B \\
\hline ; & c & C & C. & & $C_{-}$ & C. & C & C_ & C \\
\hline B & A & A & A. & & A & A & $A_{-}$ & A & A \\
\hline$B$ & B & B & B. & & B & B_ & B & B & B \\
\hline & $\mathrm{C}$ & & C & & $C$ & $C$ & $r$ & S & $r$ \\
\hline
\end{tabular}

Set number 3

\begin{tabular}{|c|c|c|c|c|c|c|c|c|c|c|c|c|c|c|}
\hline LB & C. & C & C. & C. & C & C & $c$ & & C & $C_{-}$ & 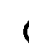 & & C & $C_{-}$ \\
\hline 2B & A. & $A_{-}$ & A & A & $F$ & 5 & $f$ & & A & A & & & & A \\
\hline B & B. & B_ & B & B. & B & $E$ & I & & $B_{-}$ & B. & & & B & B. \\
\hline B & C. & C. & C. & C. & C & C & $c$ & & C & C. & & & C & C. \\
\hline$B$ & $A_{-}$ & A & $A_{-}$ & A & $\mathrm{A}$ & $A$ & & & A & A & & & & A \\
\hline $6 \mathrm{~B}$ & B_ & $B_{-}$ & B & B. & B & $E$ & & & $\mathrm{~B}_{-}$ & B. & & & B & B. \\
\hline B & C. & C. & C & C. & & $c$ & & & C_ & C. & & & C & C \\
\hline $3 B$ & $A$ & A & A & A. & & & & & & & & & & \\
\hline B & $B$ & B & B & $B$ & & & & & & $R$ & & & & $R$ \\
\hline
\end{tabular}




\section{Appendix $\mathrm{H}$ \\ Scoring Sheet for Retention and Transfer \\ Trials for Pilot study}

Retention and transfer trials will be random for random and blocked acquisition groups.

$$
A=12 \text { yds. } \quad B=18 \text { yds. } \quad C=22 \text { yds. }
$$

Retention trials

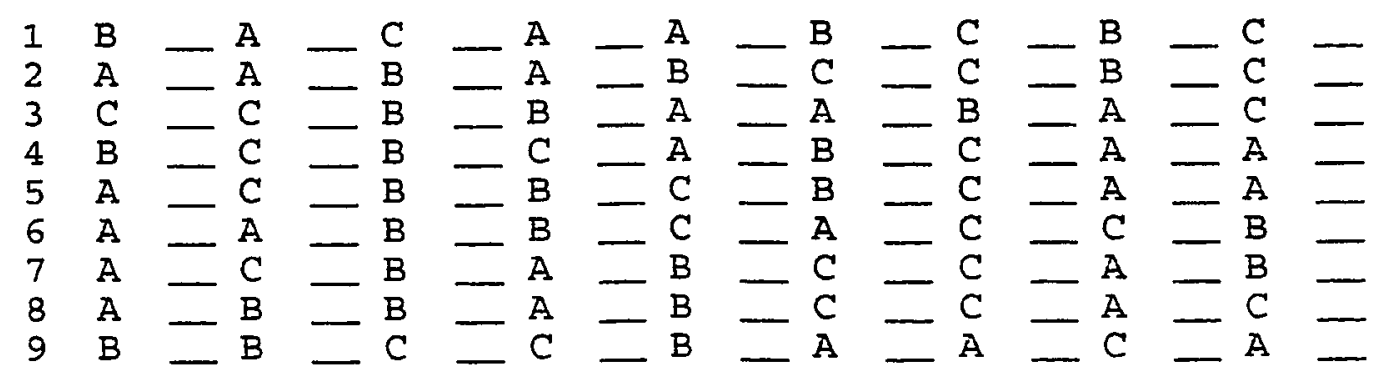

Transfer trials

$$
X=20 \text { yds. } \quad Y=25 \text { yds. }
$$

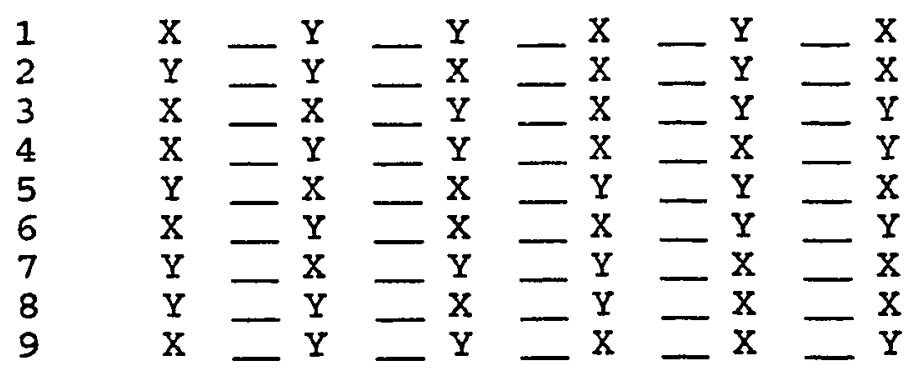


Appendix I

Shooting Distances for Transfer Tests for Pilot study

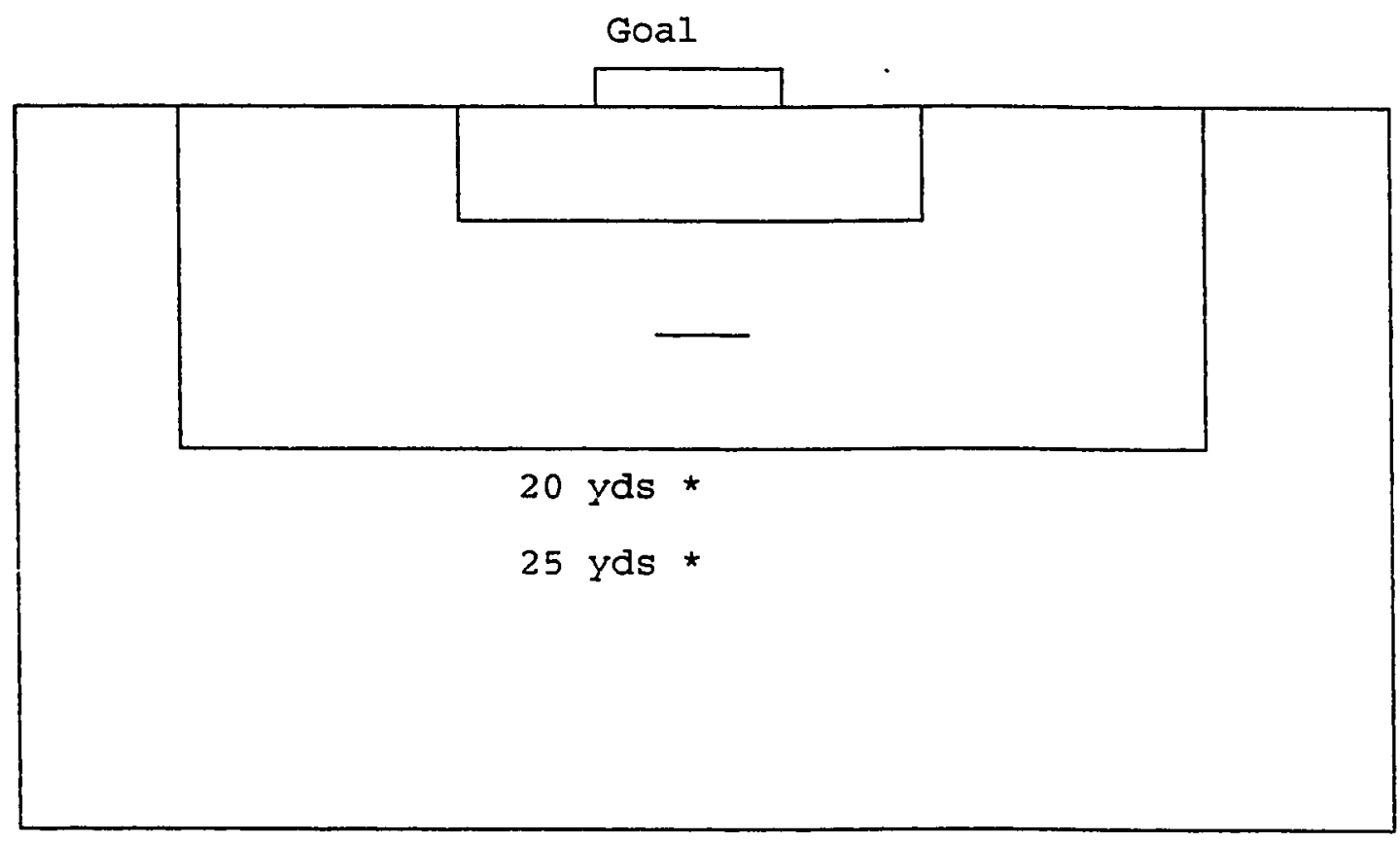




\section{Appendix J \\ Consent Form for Main study}

My child or ward has been

asked to participate in a research study entitled Effects of Contextual Interference on Acquisition, Retention and Transfer of Shooting a Moving Soccer Ball, to be conducted for two weeks at a practice site determined by (high school and coach's name), under the direction of Edward H. Mattson. There are no anticipated risks. The subjects may benefit in shooting accuracy when kicking a moving soccer ball.

The procedures have been explained to me and my child and we understand them. They are as follows: the purpose of this study is to determine the effects of contextual interference on the acquisition, retention and transfer of shooting a soccer ball at different distances. The task involves kicking a soccer ball at a target goal as accurately as possible from different distances. Experimental procedures will include four sessions. The first three sessions will consist of 12 trials per day and will last approximately 30 minutes each day. The fourth session will consist of 15 trials and will last approximately 45 minutes. The first test will be preceded by an orientation to the field test in which all procedures will be explained, and an opportunity to ask questions and to warm up will be given. 
We understand that this consent and data may be withdrawn at any time without penalty. We have been given the right to ask questions, and our questions, if any have been answered to our satisfaction. We understand that there is no compensation for participation in this study. We understand the data will be reported in group form and individual data will be kept confidential.

If we have any complaints about the research we can contact Dr. Bryant, Ph.D, Chair of Human Performance Department, at (408) 924-3010. Questions or complaints about research, subjects' rights, or research-related injury may be presented to Serena stanford, Ph.D., Associate Academic Vice President for Graduate Studies and Research, at $(408) \quad 924-2480$.

We have received a copy of this consent form. The signature of the parent or guardian on this document indicates approval for the child or ward to participate in the study and a statement that the child or ward is freely willing to participate.

\begin{tabular}{lll}
\hline Name of Child or Ward & & \\
\hline Parent or Guardian Signature & & Date \\
\hline Relation to Child or Ward & Date
\end{tabular}


Appendix K

Descriptive Soccer Questionnaire for Main study

Subject's or child's name:

Birth year:

$\begin{array}{lllll}1976 & 1977 & 1978 & 1979 & 1980\end{array}$

Birth Month:

Jan Feb Mar Apr May Jun Jul Aug sep Oct Nov Dec

Total years of soccer experience:

Total years of varsity soccer experience:

Total years of jr. varsity soccer experience:

Which team do you expect to play this year:

$$
\text { Varsity Jr. Varsity }
$$

Position:

Goalie Defender Midfielder Forward

Dominant kicking foot: Right Left

Have you ever scored a goal in a game? Yes No

How many goals have you scored in your last two seasons?

DO NOT WRITE BELOW THIS LINE

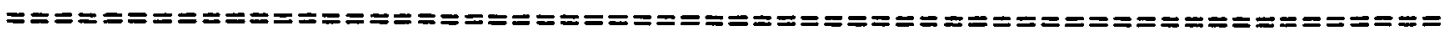

(SCHOOL NAME) SCHOOL SOCCER TEAM

Subject number:

Group assigned: Blocked Serial

Location of test site: Name of practice field 
Appendix L

Instructions for Main study

This research is designed to study the effects of two training methods, blocked and serial, on acquisition, retention and transfer of shooting a moving soccer ball from three position distances: 12 yards in front of left goal post, 15 yards in front of center of the goal and 18 yards in front of the right goal post.

Subjects will be evenly divided into two groups, blocked and serial. There will be 3 acquisition test days and one day on which retention and transfer will be tested. One group will shoot at goal while the other group helps retrieve shots.

During acquisition subjects in each group will shoot 12 trials in a rotating order. After one group has completed the acquisition trials, the groups will switch. During retention and transfer each group will shoot 9 retention trials and 6 transfer trials. Both retention and transfer trials will be randomly assigned by the researcher. Subjects are limited to use the inside or instep to kick the ball because these parts of the foot offer the greatest degree of accuracy and power. If another part of the foot is used such as the toe, a score of zero will be recorded for that trial. Subjects' goal is to be as 
accurate as possible with the type of kicks allowed, while shooting at the target goal.

The target goal is comprised of a regulation soccer goal, 8 by 24 foot, the crossbar, the side poles and a 3 by 4 foot area adjacent to the side poles. The soccer goal is divided into 4 by 4 foot squares ranging from 2 to 6 points (a picture of the target goal will be available near the researcher). If the ball hits the rope the lower point value will be awarded. The crossbar and side poles are worth "I" point each if the ball hits and rebounds into the field of play. The 3 by 4 foot area adjacent to the goal posts are worth "1" point if the ball hits it regardless of how the ball rebounds. Do you have any questions? The goal of this study is to be as accurate as possible while trying to obtain the highest amount of points. 
Appendix $M$

Shooting positions for Pretest. Acquisition

Retention and Transfer Trials

for Main Study

Normal markings on a soccer field and the locations of the pretest, acquisition and retention, and transfer positions.

Goal

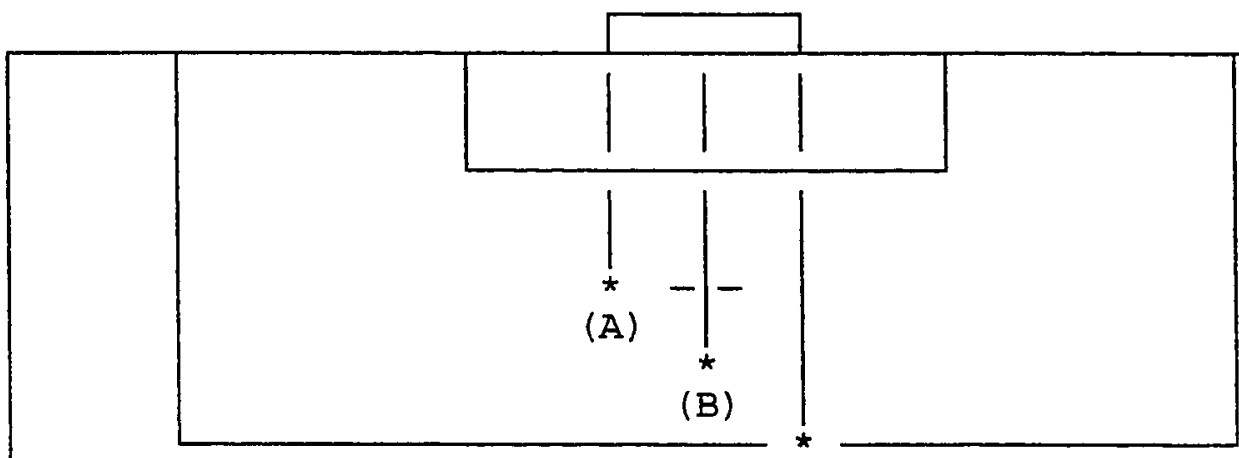

(C)

These are the acquisition and retention positions.

(A) 12 yds. in front of the left goal post.

(B) 15 yds. in front of the center of the goal.

(C) 18 yds. in front of the right goal post.

These are the pretest and transfer ball positions.

(P) 12 yds. in front of the center of the goal (pretest)

(X) 12 yds. in front of the right goal post (transfer).

(Y) 18 yds. in front of the left goal post (transfer).

(Y)

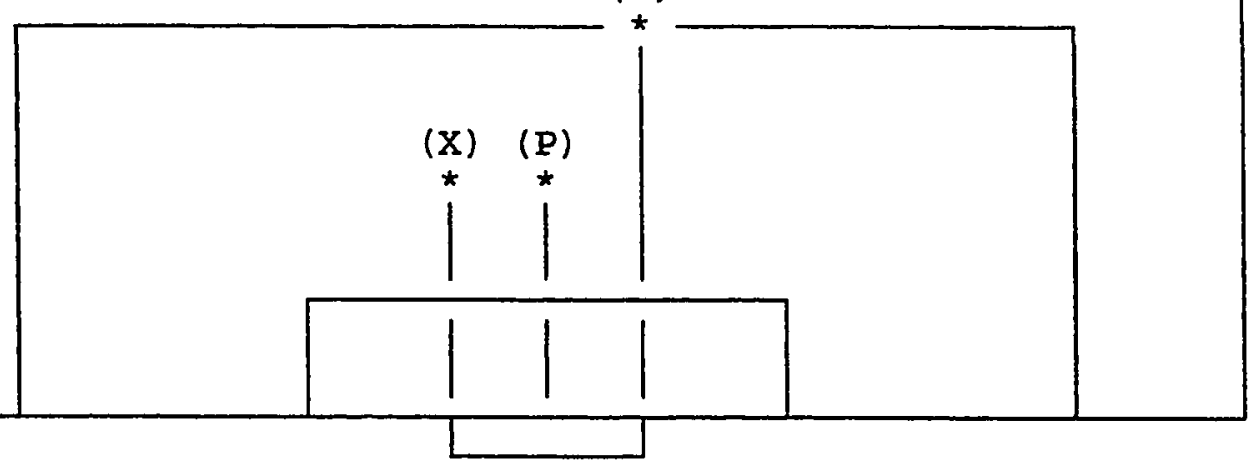


Appendix $\mathrm{N}$

Sample Acquisition Trial Scoring Sheet for Main study

SERIAL GROUP

DAY 1

$T=$ Trial Distance

$A=12$ yds. in front of left goal post.

$B=15 \mathrm{yds}$. in front of center of goal.

$C=18$ yds. in front of right goal post.

$S=$ Score for hitting target goal.

TS TSTSTSTSTSTSTSTSTSTSTS

$1 S A-B-C-A-B-C-A-B-C-A-B-C-$
$2 S A-B-C-A-B-C-A-B-C-A-B-C-$
$3 S A-B-C-A-B-C-A-B-C-A-B-C-$
$4 S A-B-C-A-B-C-A-B-C-A-B-C-$
$5 S A-B-C-A-B-C-A-B-C-A-B-C-$
$6 S A-B-C-A-B-C-A-B-C-A-B-C-$
$7 S A-B-C-A-B-C-A-B-C-A-B-C-$
$8 S A-B-C-A-B-C-A-B-C-A-B-C-$
$9 S A-B-C-A-B-C-A-B-C-A-B-C-$
$10 S A-B-C-A-B-C-A-B-C-B-B-B-C$

BLOCKED GROUP

\begin{tabular}{|c|c|c|c|c|c|c|c|c|c|c|c|c|c|}
\hline 1B & A & A_ & A_ & A & A & A & $A_{-}$ & A & A & & & A_ & A \\
\hline $4 B$ & A & A & A & A & A & A & A & A_ & A & & & A & A \\
\hline $7 B$ & A & A & A & A & A & A & A & A & A & & & A _ & A \\
\hline $10 B$ & A & A & $A_{-}$ & A & A & A & A & A_ & A & & & A_ & A \\
\hline $2 \mathrm{~B}$ & B & B_ & B & B. & B & B & B & B & B & & & & B \\
\hline $5 B$ & B_ & B_ & B. & B & B_ & B & B_ & B_ & B_ & & & B_ & B \\
\hline $8 B$ & B & B & B & B & B & B & B_ & B & B & & & B_ & B \\
\hline $3 \mathrm{~B}$ & C. & $c_{-}$ & C & C. & C_ & C. & C & C & c & & & c & $C$ \\
\hline $5 B$ & $C_{-}$ & C_ & C_ & C_ & C_ & $C_{2}$ & C_ & $C_{-}$ & c & & & c_ & C \\
\hline & $C$ & $\mathrm{C}$ & 0 & $C$ & $C$ & $\mathrm{C}$ & $C$ & C & C & & & C_ & C \\
\hline
\end{tabular}




\section{Appendix 0}

Retention and Transfer Trial score sheet for Main Study

\section{BLOCKED OR SERIAL GROUP}

Retention and transfer trials will be random for both serial and blocked acquisition groups.

Trial Distance $A=12$ yds. in front of left goal post.

$B=15 \mathrm{yds}$. in front of center of goal.

$C=18$ yds. in front of right goal post.

\section{RETENTION TRIALS}

$1 B-A-C-A-A-B-C-B-C$

$2 A-A-B-A-B-C-C-B-C$

$3 C-C-B-B-A-A-B-A-C$

$4 B-C-B-C-A-B-C-A-A-$

$5 A-C-B-B-C-B-C-A-A-$

$6 A-A-B-B-C-A-C-C-B-$

$7 A-C-B-A-B-C-C-A-B-$

$8 \mathrm{~A}-\mathrm{B}-\mathrm{B}-\mathrm{A}-\mathrm{B}-\mathrm{C}-\mathrm{C}-\mathrm{A}-\mathrm{C}$

$9 B-B-C-C-B-A-A-C-A-$

$10 B-A-C-A-A-B-C-B-C-$

TRANSEER TRIALS

$x=12$ yds. in front of right goal post.

$Y=18$ yds. in front of left goal post.

$\begin{array}{rl}1 & X-Y-Y-X-Y-X \\ 2 & Y-Y-X-X-Y-X \\ 3 & X-X-Y-X-Y-Y \\ 4 & X-Y-Y-X-X-Y \\ 5 & Y-X-X-Y-Y-X \\ 6 & X-Y-X-X-Y-Y \\ 7 & Y-X-Y-Y-X-X \\ 8 & Y-Y-X-Y-X-X \\ 9 & X-Y-Y-X-X-Y \\ 10 & X-Y-Y-X-Y-X\end{array}$

